\title{
Das württembergische Einkommensteuergesetz vom 8. August 1903
}

\author{
Von Matthias H. Gehm
}

\section{Einführung}

In Art. 13 der französischen Erklärung der Menschen- und Bürgerrechte vom 3. Januar 1789 steht bereits: „Für die Unterhaltung der Streitmacht und für die Kosten der Verwaltung ist ein gemeinschaftlicher Beitrag unerlässlich; dieser soll unter alle Bürger des Staates im Verhältnis zu ihren Vermögensverhältnissen auf gleiche Weise verteilt werden “1. Hieraus ergab sich dann in der Folgezeit der Gedanke einer allgemeinen Einkommensteuer mit steigendem Steuersatz entsprechend der persönlichen Leistungsfähigkeit. Die moderne progressive Einkommensteuer wurde aber nicht in Frankreich, sondern im Gegenteil von dessen Erzrivalen, nämlich Großbritannien, im Jahr 1799 zur Finanzierung des Krieges gegen Frankreich eingeführt ${ }^{2}$. Als erster deutscher Staat folgte sodann Preußen auf Anregung von Karl Freiherr vom Stein dem britischem Vorbild im Jahr 1808 und führte für Ost-/ Westpreußen, Litauen, Königsberg und Danzig ebenfalls die progressive Einkommensteuer $^{3}$ zur Aufbringung der an Frankreich zu zahlenden Kriegskontributionen ein. Diese Steuer wurde dann ausgeweitet, in der Folgezeit jedoch wie in England nach Kriegsende wieder aufgehoben, da die Bevölkerung den entsprechenden tiefen Eingriff in ihre private Einkommenssphäre nur bei einer entsprechenden staatlichen Notlage bereit war zu tolerieren.

Der Ursprung der Einkommensteuer liegt mithin in einer Kriegssteuer. Gerade die deutsche Linke war sodann ein Verfechter dieser Idee, die insofern im Zuge der Revolution von 1848/49 mit Nachdruck auf die politische Tagesordnung kam. So forderten Karl Marx und Friedrich Engels bereits in ihrem im Februar 1848 er-

\footnotetext{
${ }^{1}$ Joachim Lang: Leistungsfähigkeitsprinzip. In: Steuerrecht. Hg. von Joachim Lang und Klaus Tipke. ${ }^{20} 2010 . \$ 4$, Rn. 82.

2 Bernhard Großfeld: Die Einkommensteuer - Geschichtliche Grundlage und rechtsvergleichender Ansatz. 1981. S.7ff. - C.H.P. Inhülsen: Die geschichtliche Entwicklung und heutige Gestaltung der englischen Einkommensteuer. In: Finanzarchiv 13 (1896) S. 253-272.

${ }^{3}$ Gesetz vom 23. März 1808. Gesetz-Sammlung für die Königlich Preußischen Staaten 1806-1810. S. 193.
} 
schienenen „Manifest der Kommunistischen Partei“ eine „starke Progressivsteuer“ - gemeint war damit auch die Einkommensteuer. Ferdinand Lassalle griff diese Ideen denn auch in seiner Schrift „Die indirekte Steuer und die Lage der Arbeitenden Klasse“ im Jahre 1863 auf und forderte die Abschaffung aller indirekten Steuern und stattdessen die Einführung der Einkommen- und Erbschaftsteuer ${ }^{4}$.

Hier soll nun die Geschichte des württembergischen Einkommensteuergesetzes vom 8 . August $1903^{5}$ vorgestellt werden. In diesem Zusammenhang sei hervorgehoben, dass sich unter anderem der Zentrumspolitiker und spätere Reichsfinanzminister Matthias Erzberger publizistisch für die Einkommensteuer in seiner württembergischen Heimat einsetzte. Württemberg selbst zählte dabei zu einem der letzten deutschen Länder - war doch die Gesetzgebung auf diesem Gebiet im Kaiserreich den Bundesstaaten vorbehalten - die eine allgemeine Einkommensteuer einführten. Insofern konnte man hier aber auf den Erfahrungen anderer Länder aufbauen und eine moderne Besteuerungsform installieren.

\section{Das Wirken von Matthias Erzberger in der württembergischen Steuerfrage}

Matthias Erzberger, von Beruf Volksschullehrer und Publizist, hatte sich teils als Autodidakt und teils durch ein einjähriges Studium an der katholischen Universität Fribourg (Schweiz) ein fundiertes Fachwissen auf dem Gebiet des Steuerwesens, der Finanzwissenschaft, Wirtschafts- und Sozialpolitik angeeignet. Schon frühzeitig wurde man in Zentrumskreisen auf das politische Talent Erzbergers aufmerksam, so fand er im Redakteur des in Stuttgart erscheinenden Zentrumsorgans „Deutsches Volksblatt“, dem katholischen Geistlichen Josef Eckard, und später in dem führenden württembergischen Zentrumspolitiker und Landtagsabgeordneten Adolf Gröber seine Förderer. Erzberger engagierte sich in der christlichen Gewerkschaftsbewegung und wurde insofern zu einem eifrigen Vertreter der damals noch jungen katholischen Soziallehre, wobei er schnell eine große Popularität errang und als „Anwalt der kleinen Leute“ galt. Im Jahr 1896 wurde er Redakteur des „Deutschen Volksblatts“, wo er von Gröber und Eckard beauftragt wurde, als Landtagsberichterstatter die Steuerreform in Württemberg zu kommentieren. Im Jahr 1899 erschien seine viel beachtete Broschüre mit dem Titel „Steuerreform in Württemberg", in welcher er eine progressive Einkommensteuer unter Berücksichtigung des Leistungsfähigkeitsprinzips, stärkere Belastung der Kapitaleinkommen gegenüber der Landwirtschaft, Einführung eines ausreichenden Grundfreibetrages als Kompensation der kleineren Einkommen für die starke Belastung mit indirekten Steuern und Berücksichtigung außergewöhnlicher Belastungen

${ }^{4}$ Dieter Birk: Steuerecht. ${ }^{13} 2010$. Rn. 19.

${ }^{5}$ Regierungsblatt für das Königreich Württemberg 1903. S.261. 
(Krankheiten, Unglücksfälle etc.) sowie steuerliche Entlastung von kinderreichen Familien einforderte. Das Argument der Württembergischen Volkspartei, dass dies zu einer Kapitalflucht bzw. Abwanderung der Industrie aus Württemberg führen könne, ließ Erzberger demgegenüber nicht gelten ${ }^{6}$.

Über das Zustandekommen des Einkommensteuergesetzes resümierte Erzberger sodann in den „Historisch-politischen Blättern“, dass dieses Gesetz wie die anderen Gesetze der württembergischen Steuerreform „in ganz hervorragender Weise von einem socialen Verständniß getragen“ sei. Insbesondere hob er hervor, dass auf die individuelle Leistungsfähigkeit des Steuerpflichtigen im Unterschied zu den alten württembergischen Ertragsteuern, denen solch ein Ansatz weitgehend fremd war, Rücksicht genommen worden sei. Davon profitierten, wie Erzberger hervorhob, die teils beträchtlich verschuldeten landwirtschaftlichen Betriebe Württembergs, denen ein Schuldzinsenabzug gewährt wurde.

Erzberger, der 1899 auch einen Bauernverein gegründet hatte, lag das Wohl der Landbevölkerung in der Steuerfrage sehr am Herzen. Zusätzlich stellte er auf die Gerechtigkeit der Progression ab, die den Mittelstand entlaste und die Steuerfreiheit von Geringverdienern. Die Strafbestimmungen im Einkommensteuergesetz sah er als „scharf, aber gerecht“ $a^{7}$. Insofern sei nun ein neues Steuersystem entstanden, „das mit Fug und Recht sich als das erste, social gerechteste und freisinnigste aller deutschen, ja europäischen Steuergesetze bezeichnen darf“. Erzberger zumindest beeinflusste somit in der württembergischen Steuerfrage die Zentrumsanhänger. Da Gröber sowohl im Hinblick auf den Einkommensteuergesetzesentwurf von 1895 als auch hinsichtlich der Beratung zum Einkommensteuergesetz von 1903 von der Abgeordnetenkammer zum Berichterstatter gewählt worden war, konnte Erzberger auch auf diesem Weg Einfluss auf das württembergische Gesetzgebungsverfahren nehmen. Umgekehrt wird Erzberger aber auch in

${ }^{6}$ Matthias Erzberger: Die Steuerreform in Württemberg. Rede des Redakteurs Erzberger, gehalten in der Versammlung des Windthorstbundes am 22. Februar 1899. In: Flugblätter des Deutschen Volksblatts Stuttgart (1899) Nr. 2. - Christopher Dowe: Anwalt der kleinen Leute. In: Matthias Erzberger - Ein Wegbereiter der Deutschen Demokratie. Hg. vom Haus der Geschichte Baden-Württemberg. Stuttgart 2011. S.22-32. - Wolfgang Ruge: Matthias Erzberger - eine politische Biographie. ${ }^{1} 1971$. S. 9 ff. - Alex Möller: Reichsfinanzminister Matthias Erzberger und sein Reformwerk. ${ }^{1} 1971$. S. 9 ff. - Wolfgang Michalka: Matthias Erzberger: > Reichsminister in Deutschlands schwerster Zeit<. 2002. S. 37, 44 ff. Alfons Pausch: Matthias Erzberger - Reichsfinanzminister von 1919/20. Wegbereiter einer einheitlichen, neuen Steuerordnung für ganz Deutschland. In: Steuer und Studium (1989) S. 341-348, 342. - Ders.: Matthias Erzberger - Sein Leben und Werk. 1965. S. 10 ff. - Rudolf Morsey/Wolfgang Schäuble: Matthias Erzberger - Ein Wegbereiter deutscher Demokratie. 2001. - Rudolf Morsey: Matthias Erzberger (1875-1921). In: Zeitgeschichte in Lebensbildern - aus dem deutschen Katholizismus des 20. Jahrhunderts. Hg. von Rudolf Morsey. 1973. S. 103-112. - Michail Krausnick/Günter Randecker: Matthias Erzberger. Konkursverwalter des Kaiserreichs und Wegbereiter der Demokratie. 2005. S. $17 \mathrm{ff}$.

7 Christian Leitzbach: Matthias Erzberger - Ein kritischer Beobachter des Wilhelminischen Reichs 1895-1914. 1997. S.227ff. 
dieser Frage vom juristischen Sachverstand seines politischen Ziehvaters Gröber, der von Beruf her Landrichter war, profitiert haben, so dass von einer gegenseitigen Beeinflussung der beiden Zentrums-Politiker auszugehen ist.

Im Zuge der Reichstagswahlen vom 16. Juni 1903 errang Erzberger den württembergischen Wahlkreis Biberach-Leutkirch-Waldsee-Wangen und zog mit 28 Jahren als jüngster Abgeordneter in den Reichstag. Wegen seiner in Württemberg gewonnenen Erfahrungen erhielt er bereits 1904 einen Sitz in der Budgetkommission - dem damaligen Haushaltsausschuss des Reichstages ${ }^{8}$. Aufgrund seines steuerpolitischen Programms, das Erzberger bereits im Zusammenhang mit der Einkommensteuerreform in Württemberg entwickelte, verwundert es nicht, dass er als Reichsfinanzminister die Sozialisierungstendenzen seiner Steuerpolitik unter Akzentuierung des Leistungsfähigkeitsprinzips in den Mittelpunkt seiner Reformen stellte?

\section{Württembergs Ertragsteuersystem}

In Württemberg entstand bereits sehr früh ein Ertragsteuersystem. Durch Ertragsteuern werden jedoch nur gewisse Einkunftsquellen bzw. Objekte belegt; nämlich Grund und Boden, Gebäude und Gewerbebetriebe. Dabei knüpfte die Besteuerung an äußeren Merkmalen, wie in der Landwirtschaft der Größe einer Parzelle oder bei Gebäuden der Anzahl der Fenster eines Hauses bzw. bei Gewerbebetrieben der Art des ausgeübten Gewerbes, an. Die persönliche Leistungsfähigkeit des Steuerpflichtigen, wie die Berücksichtigung berufsbedingter Aufwendungen trat im Unterschied zu einer modernen Einkommensteuer in den Hintergrund ${ }^{10}$.

Einen der Eckpunkte der württembergischen Steuergeschichte bildete der Tübinger Vertrag vom 8. Juli 1514. Durch ihn übernahmen die Landstände die beträchtlichen Schulden des Herzogs Ulrich und richteten zu ihrer Rückzahlung eine Tilgungskasse ein. Im Gegenzug verlieh der Herzog dem Landtag das Steuerbewilligungsrecht. Als Folge dieses Vorgangs entstand im 16. Jahrhundert die „Ablösungshilfe“. Diese Steuer wurde von den Ständen auf Grundeigentum, Gebäude, Gewerbe, Geldgüter und verzinsliche Kapitalien mit einem Steuersatz von regelmäßig 5\% des Vermögens gelegt. Die Ablösungshilfe verfestigte sich allmählich als jährliche Steuer, wobei sie sodann die Bezeichnung „Ordinaristeuer“ erhielt. Die

8 Theodor Eschenburg: Matthias Erzberger. 1973. S. 8 ff. - Frank Raberg: Biographisches Handbuch der württembergischen Landtagsabgeordneten 1815-1933. 2001. S. 286 ff. - Theodor Pistorius: Die württembergische Steuerreform. In: Finanzarchiv 21 (1904) S. 1-234, 20 f., 23. - Alfons Pausch: Persönlichkeiten der Steuerkultur - Steuergeschichte in Lebensbildern von Johannes von Miquel bis Arnim Spitaler. 1992. S. $32 \mathrm{ff}$.

9 Gabriele Höfler: Erzbergers Finanzreform und ihre Rückwirkung auf die bundesstaatliche Struktur des Reiches vorwiegend am bayerischen Beispiel. 1955. S. 30.

10 Matthias Gehm: Württembergs Einkommensteuergesetz vom 8. August 1903. Vom Ertragsteuersystem zur Besteuerung nach der persönlichen Leistungsfähigkeit. 2011. S. $7 \mathrm{ff}$. 
Möglichkeit des Schuldenabzugs war bei dieser Steuer nur eingeschränkt gegeben. Bei der Ordinaristeuer wurde die Gesamtsteuerlast auf die Ämter bzw. Gemeinden verteilt, die diese sodann auf die Steuerbürger nach einer gewissen örtlichen Übung umlegten (Repartitionssteuersystem - Unterverteilungssteuer). Im 17. Jahrhundert erfolgte dann die Erstellung von Steuerkatastern, in welchen Grundstücke, Häuser, Kapitalien und Gewerbe aufzuzeichnen waren. Im Jahr 1714 führte Württemberg durch die Umbildung der Ordinaristeuer ein System von Ertragsteuern ein, welches auf einem neuen Kataster beruhte, welches 1744 abgeschlossen war. Belegt wurden nunmehr die Grundstücke, Grundgefälle ${ }^{11}$, Gebäude und die Gewerbe. Der Ertrag wurde hierbei allerdings recht schematisch bestimmt. So wurde bei Gebäuden der Kapitalwert, welcher sich am Verkaufswert ausrichtete, als Ertrag angesehen. Bei Grundstücken wurden Güteklassen gebildet. Allerdings verblieb es dabei, dass hierdurch nur das Steueraufkommen durch die Ämter bestimmt wurde, die Umlage auf die einzelnen Steuerbürger erfolgte wiederum nach dem örtlichen Herkommen.

Unter König Friedrich (reg. 1797-1816, ab 1806 König) begann ein Umbau des Steuersystems, insbesondere ging die Steuerverwaltung- und -erhebung von den Ständen auf die königliche Regierung über. König Wilhelm I. (reg. 1816-1864) führte die Reformen weiter, wobei mit dem Gesetz, die Herstellung eines provisorischen Steuerkatasters betreffend vom 15. Juli $1821^{12}$, die Grund-, Gebäude- und Gewerbesteuer im Zuge einer allgemeinen Steuerpflicht als Fortentwicklung der alten Ordinaristeuer angestrebt wurde. Ergänzt wurde das Gesetz durch Verfügung des Departements der Finanzen vom 28. Juli $1821^{13}$. Bei der Grundsteuer war Steuergegenstand der Ertrag, bei der Gebäudesteuer der Kapitalwert als Verkaufswert und bei der Gewerbesteuer die durchschnittliche Kapital- und Arbeitsrente, jedoch hier ohne Möglichkeit des Schuldenabzugs. Hierbei fanden mehr oder weniger standardisierte Schätzungen nach Ertragsklassen hinsichtlich der erwarteten Erträge statt. Für den Steuereinzug waren die Gemeinden zuständig.

Da bei den drei Ertragsteuerarten im Zuge des Repartitionssteuersystems die aufzubringende Steuerlast festgelegt wurde, entfielen somit bis 1877 von den insgesamt aufzubringenden jährlichen Steuern von 2,4 Mio. Gulden auf das Grundeigentum - ohne Gefälle - 1.7 Mio., auf Gebäude 400.000 und auf Gewerbe 300.000 Gulden (Verteilungsmaßstab also $17: 4$ :3; ab dem Etatjahr 1877/78 wurde dies auf einen Verteilungsmaßstab von $13: 5,5: 5,5$ umgestellt $)^{14}$. Dass dies im Verlauf des 19. Jahrhunderts sehr bald nicht mehr zeitgemäß war, liegt auf der Hand, machte doch bereits im Jahr 1863 die Land- und Forstwirtschaft nur noch 49,5\% der Wert-

${ }^{11}$ Gefälle waren in der Grundherrlichkeit die dem Berechtigten zufließenden Geld- und Naturalleistungen.

${ }^{12}$ Regierungsblatt (wie Anm. 5) 1821. S. 457.

13 Regierungsblatt (wie Anm. 5) 1821. S. 549.

14 Regierungsblatt (wie Anm. 5) 1873. S. 261, 262. 
schöpfung Württembergs aus, während die Quote bei Bergbau, Gewerbe und Handel bereits bei 44,7\% lag.

Das Ertragsteuersystem war aber nicht gänzlich bedeutungslos für die Entwicklung der Einkommensteuer in Württemberg. So enthielt das Ertragsteuergesetz vom 28. April $1873^{15}$ Bestimmungen, die auch das Einkommensteuergesetz von 1903 Vorbildfunktion prägten. Hiernach bestand das Prinzip der Allgemeinheit der Besteuerung, im Besteuerungsverfahren wurden Schätzungskommissionen tätig, bei denen die Gemeindeverwaltungen eingebunden waren, den Steuerpflichtigen trafen gewisse Mitwirkungs- und Erklärungspflichten, Steuerhinterziehung wurde mit dem vierfachen Verkürzungsbetrag als Geldstrafe geahndet, wobei die Möglichkeit der Ersatzfreiheitsstrafe gegeben war, es bestand die Möglichkeit zur strafbefreienden Selbstanzeige.

Mit Gesetz vom 19. September $1852^{16}$ wurde, nachdem bereits früher temporär Besoldungs-, Pensions- und Kapitalsteuern existierten, die sich im Laufe der Zeit verfestigten, eine Steuer auf Kapital-, Renten-, Dienst- und Berufseinkommen erhoben, die in Richtung einer Einkommensteuer wies, auch wenn sie viele Merkmale einer modernen Einkommensteuer nicht besaß, insbesondere was wiederum die Frage nach der ausreichenden Berücksichtigung der persönlichen Leistungsfähigkeit anbelangt. Die Steuersätze wurden in den jeweiligen Finanzgesetzen festgelegt, wobei der Steuersatz progressiv ausgestaltet war. Letztere Steuer wurde mit mehrfachen Änderungen bis zur Steuerreform des Jahres 1903 erhoben. Erst mit Wirkung ab 1. April 1887 wurde ein einheitlicher Steuersatz als Quotitätssteuer (Anteilsteuer) in Höhe von 3,9\% bei Grund-, Gebäude und Gewerbesteuer bestimmt. Weiterhin wurde die Bemessungsgrundlage für die Ertragsbesteuerung durch Steuerkataster gewonnen. Bei der Steuerreform des Jahres 1903 besaß damit Württemberg ein Ertragsteuersystem aus fünf Steuerarten nämlich Gefällsteuer einschließlich Grundsteuer, Gebäudesteuer, Gewerbesteuer, Kapitalsteuer und Dienst- und Berufseinkommensteuer ${ }^{17}$.

15 Regierungsblatt (wie Anm. 5) 1873. S. 127.

${ }_{16}$ Regierungsblatt (wie Anm. 5) 1852. S.230.

$17 \mathrm{Gehm}$ (wie Anm. 10) S. 7 ff. - Ministerielle Denkschrift betreffend die Fortführung der Steuerreform in Württemberg vom 19. März 1909. In: Finanzarchiv 27 (1910) S.394-479, 394 ff. - Pistorius (wie Anm. 8) S. 1-234. - Otto von Sarwey: Das Staatsrecht des Königreichs Württemberg. 1883. S. $103 \mathrm{ff}$. - Friedrich Stumpff: Die geschichtliche Entwicklung des württembergischen Staatssteuerwesens in allgemeinen Zügen. In: Zeitschrift für die gesamte Staatswissenschaft (1905) S. 710-724. - Karl von Riecke: Die direkten Steuern vom Ertrag und vom Einkommen in Württemberg. In: Württembergische Jahrbücher für Statistik und Landeskunde (1879) S.71-205, 77 ff. - Ulrike Metzger/Joe Weingarten: Einkommensteuer und Einkommensteuerverwaltung in Deutschland. 1989. S. 58 ff. - Eckart Schremmer: Einfach und gerecht? Die erste deutsche Einkommensteuer von 1874/78 in Sachsen als Lösung eines Reformstaus in dem frühindustrialisierten Land. In: Integriertes Steuer- und Sozialsystem. Hg. von Manfred Rose. 2003. S. 191-214, 194. - Mark Spoerer: Steuerlast, Steuerinzidenz und Steuerwettbewerb - Verteilungswirkungen der Besteuerung in Preußen und Württemberg (1815-1913). 2004. S.23, 84 ff., 94 f. - Georg von Mayr: Württembergische 


\section{Die politische Forderung nach einer Einkommensteuer für Württemberg}

Damit, dass Württemberg, wenn auch teilweise etwas später und etwas langsamer als andere deutsche Staaten, seit den 90er Jahren des 19. Jahrhunderts von einem Industriewachstum profitierte, auch wenn die in der Landwirtschaft tätige Bevölkerung noch rund die Hälfte der Gesamtbevölkerung ausmachte und industrielle Großbetreibe eher die Ausnahme waren, erwiesen sich das steuerliche Katastersystem und die hierauf beruhenden Ertragsteuern zunehmend mit ihrem weitgehend nur geschätzten Ertrag als nicht mehr realitätsnah. Das Gebot der Stunde war in Anbetracht der wirtschaftlichen Rahmenbedingungen, ein flexibles Steuersystem zu schaffen. Umgekehrt musste in der Steuerfrage den Interessen der mittelständischen Industrie wie der Landwirtschaft Rechnung getragen und die Möglichkeit für die Ansiedelung bzw. das Wachstum von Großbetrieben eröffnet werden. Gleichzeitig bestand die politische Forderung, gerade im Hinblick auf die ärmeren Bevölkerungsschichten das Leistungsfähigkeitsprinzip in der Ertragsbesteuerung zu verankern. Dass solches möglich war, erwiesen die Einkommensteuergesetzgebungen anderer deutscher Staaten jener Zeit ${ }^{18}$.

Insofern stellten die Landtagsabgeordneten Karl von Göz von der Deutschen Partei - einer den Nationalliberalen entsprechenden politischen Gruppierung -, Dr. Karl Schall und 22 weitere am 12. Juni 1889 an die Finanzkommission den Antrag, eine (ergänzende) allgemeine Personalsteuer einzuführen, die in Richtung einer Einkommensteuer weisen sollte. Die Kammer der Standesherren schloss sich diesem Antrag an, worauf das Finanzministerium in der Folgezeit dieses Projekt in Angriff nahm. Die Kammer der Abgeordneten selbst hatte zu dieser Frage sodann am 13. Juni 1889 weiter beschlossen, dass die württembergische Regierung bei dem einzubringenden Gesetzesentwurf berücksichtigen solle, dass das Dienst- und Berufseinkommen, welches bei einer Person jährlich $500 \mathrm{M}$. nicht übersteige, von der Einkommensteuer frei bleibe. Weiter beantrage die Kammer der Abgeordneten, dass bei der Einkommensteuer Schuldzinsen beim Einkommen in Abzug zu bringen seien. Insgesamt wurde das Leistungsfähigkeitsprinzip als Maxime der zu-

Steuerreformfrage. In: Zeitschrift für die gesamte Staatswissenschaft (1891) S. 253-278. Ernst Marquardt: Geschichte Württembergs. 1961. S. 60, 71, 75, 77. - Eckart Schremmer: Warum die württembergischen Ertragsteuern von 1821 und die sächsische Einkommensteuer von 1874/75 so interessant sind. 2002. S.11, 13. - Matthias Gehm: Zur Geschichte der Anfänge des deutschen Einkommensteuerrechts - 200 Jahre Einkommensteuer in Deutschland. In: Steuer und Studium (2008) S. 188-198. - K. F. von Schall: Beiträge zur Reform der direkten Steuern in Württemberg unter Berücksichtigung der Steuerreform in Preussen. In: Finanzarchiv 12 (1895) S. 1-62. - Alfred Deblinger: Württembergs Staatswesen in seiner geschichtlichen Entwicklung bis heute. 1953. \$\$377ff. - Karl von Riecke: Die neuen württembergischen Steuerkataster. In: Finanzarchiv 5 (1888) S. 320-361.

18 Spoerer (wie Anm.17) S. 20, 94 ff. - Denkschrift (wie Anm.17) S.407f. - Metzger/ Weingarten (wie Anm. 17) S. 69. 
künftigen Besteuerung von den Antragstellern angemahnt, wobei im Laufe der Diskussion gefordert wurde, dass das gesamte Einkommen des Steuerpflichtigen $\mathrm{zu}$ erfassen sei, also eine allgemeine Einkommensteuer angestrebt wurde und größere Einkommen (progressiv) stärker belastet werden sollten.

Daraufhin legte die württembergische Finanzverwaltung eine Materialsammlung der Einkommensteuergesetze der anderen Bundesstaaten an. Was speziell die Frage des steuerfreien Existenzminimums anbelangt, so stellte die Verwaltung einen Vergleich mit der Gesetzeslage in Bayern - Einkommensteuergesetz von 1881 - an. Weiter wurden vom Finanzministerium und Steuerkollegium Referenten nach Baden und Sachsen entsandt, welche sich vor Ort einen Eindruck über die dortige praktische Ausführung der Einkommensteuer und ihrer Wirkung verschaffen sollten. Sodann wurde in einigen ländlichen Regionen unter Beiziehung von Geschäftsleuten und Landwirten die badische Einkommensteuer im Zuge von Probeveranlagungen einer Feldstudie unterzogen. Insgesamt war man aber bei der Administration recht zurückhaltend, was die Einkommensteuer anbelangte, und setzte erst einmal auf das bestehende Ertragsteuersystem. Man wollte aber die diesbezügliche aktuelle Entwicklung in Preußen, wo eine Steuerreform in Gang war, weiter beobachten.

Am 14. Mai 1895 wurde der Ständeversammlung sodann der erste Entwurf eines Einkommensteuergesetzes von der Regierung vorgelegt ${ }^{19}$. In diesem Zusammenhang ist zu erwähnen, dass sich in jener Zeit die politische Gewichtung im Landtag verschob. Letzteres war für die Berücksichtigung sozialer Belange bei der Einkommensteuer von Bedeutung. Im Jahr 1895 konnte nämlich aufgrund der Landtagswahl das Zentrum eine Fraktion im württembergischen Parlament bilden. Diese betrug immerhin 18 Abgeordnete der insgesamt 70 gewählten Abgeordneten der 2. Kammer. Im vorhergehenden Landtag hatten sich am 18. Mai 1894 insgesamt 11 Abgeordnete dem Zentrum angeschlossen. Im Jahr 1895 zogen die Sozialdemokraten mit zwei Sitzen in den Landtag ein, im vorhergehenden Landtag hatten sie ab 1894 noch einen Abgeordneten gestellt. Bei der Landtagswahl des Jahres 1900 konnte die SPD mit 7 gewählten Abgeordneten in die 2. Kammer einziehen und das Zentrum mit 19. Die Sozialdemokraten hatten in Fortführung der Gedanken von Marx und Engels sich weiterhin programmatisch für die Einführung einer progressiven Einkommensteuer stark gemacht ${ }^{20}$.

Der Versuch, die Einkommensteuer aufgrund des Gesetzesentwurfs von 1895 einzuführen, scheiterte jedoch neben der Frage der Höhe des Spitzensteuersatzes, den die 2. Kammer mit $6 \%$ bemessen wollte, daran, dass man sich nicht einigen konnte, was das Mitwirkungsrecht der 1. Kammer an diesem Gesetzesvorhaben anbelangte, denn die Kammer der Abgeordneten wollte den Standesherren kein

19 Verhandlungen der Kammer der Abgeordneten des Königreichs Württemberg. 1901/1904. Beilagen-Bd.2. S. 247 ff. nebst Gegenüberstellung der Beschlüsse beider Kammern der Ständeversammlung und amtlicher Begründung des Regierungsentwurfs.

20 Gehm (wie Anm. 10) S. 62 f. 
Mitwirkungsrecht bei der konkreten Festsetzung des Steuersatzes einräumen bzw. bei der Gestaltung des Steuertarifs war kein Konsens möglich, so dass die Kammer der Abgeordneten am 16. Januar 1899 beschloss, auf die Einzelberatung der abweichenden Beschlüsse der Kammer der Standesherren nicht einzugehen und folglich das Gesetz nicht zu Stande kam.

Am 13. Dezember 1899 fasste die 2. Kammer allerdings den Beschluss, dass die Regierung aufgefordert werde, ihr einen überarbeiteten Entwurf eines Einkommensteuergesetzes vorzulegen, wobei in diesem aufgenommen werden solle, dass der konkrete Steuersatz wie im Steuergesetz von 1852 sich aus einem im Finanzgesetz bestimmten Multiplikator bezüglich der im Einkommensteuergesetz selbst niedergelegten Einheitssteuersätze ergeben solle. Sofern der entsprechende Multiplikator zu einem höheren Steuersatz als dem Einheitsteuersatz führe, solle das ordentliche Gesetzgebungsverfahren einzuhalten sein. Nachdem im Dezember 1900 eine Neuwahl der Abgeordnetenkammer stattgefunden hatte, wenn auch die parteipolitische Zusammensetzung im Wesentlichen dieselbe geblieben war, hatten sich jedoch verschiedene Personalien geändert. Die Regierung legte am 30. April 1901 einen den Beschlüssen des vorhergehenden Landtags angepassten Gesetzesentwurf zur Einkommensteuer neben einem Gesetzesentwurf zur Kapitalsteuer sowie einer Änderung zur Grund-, Gebäude- und Gewerbesteuer nebst Neuordnung der Kommunalsteuern vor ${ }^{21}$.

\section{Verfassungsrechtliche Grundlagen der Besteuerung}

Da eines der Problemfelder bei der Beratung der Einkommensteuer in Württemberg das Mitwirkungsrecht der ersten Kammer war, sollen insoweit die verfassungsrechtlichen Grundlagen des württembergischen Steuerrechts beleuchtet werden.

21 Pistorius (wie Anm. 8) S.19ff. - Karl Göz: Das Württembergische Einkommensteuergesetz vom 8. August 1903. 1903. S. 1 ff. - Metzger/Weingarten (wie Anm. 17) S. 62 f. - Leitzbach (wie Anm. 7) S. 233. - K. F. von Schall: Finanzlage, Etatsfragen und Stand der Steuerreform in Württemberg. In: Finanzarchiv 10 (1893) S. 499-558, 545 f. - Mayr (wie Anm. 17). - Paul Sauer: Von der Verfassungsreform zur Revolution. In: Das Königreich Württemberg 1806-1918. Monarchie und Moderne. Hg. von Landesmuseum Württemberg. 2006. S. 192. Von Schall (wie Anm. 17) S. 1-62. - Ministerielle Denkschrift vom 30. April 1901 betreffend die Wiederaufnahme der Reform der direkten Staatssteuern in Württemberg. In: Finanzarchiv 18 (1901) S. 862-888. - Alfons Pausch: Matthias Erzberger - Sein Leben und Werk. 1965. S.12. - Dehlinger (wie Anm. 17) \$68. - Stumpff (wie Anm. 17) S.723. - Paul Sawer: Württembergs letzter König - das Leben Wilhelms II. ${ }^{2} 1994$. S. $97 \mathrm{ff.}$., 146, $162 \mathrm{ff}$., $226 \mathrm{ff}$. Ders.: Regent mit mildem Zepter - König Karl von Württemberg. 1999. S. 264 ff. - Bericht des Geheimrats von Heß, Verhandlungen der Kammer der Standesherrn des Königreichs Württemberg. 1901/1904. Beilagen-Bd.1. Beilage Nr. 197 S. 235 ff. 
Nach der Verfassung vom 25. September 1819 waren Steuern - sowohl direkte wie indirekte - nur zulässig, wenn sich der Staatsbedarf nicht durch Staatsdomänen (Kammergut) decken ließ und die diese Deckungslücke verursachenden Staatsausgaben sich als notwendig bzw. nützlich darstellten $(\$ 109,110$ Verfassung für das Königreich Württemberg). Die entsprechende Deckungslücke als Voraussetzung für die Notwendigkeit von Steuern wurde während der Zeit des Bestehens des Königreichs Württemberg in jedem Jahr vom Parlament als gegeben erachtet ${ }^{22}$. Die Kammern hatten aber in diesem Zusammenhang nicht das Recht der Gesetzesinitiative, daher konnten Novellierungen von Steuergesetzen nur über entsprechende Petitionen an die Regierung bewerkstelligt werden. Entgegen der sonstigen Rechte der 1. Kammer, wonach Gesetze grundsätzlich der vollen Zustimmung beider Kammern bedurften, konnten die 1 . Kammer gemäß \$181 der Verfassung nur im Ganzen mit „Ja“ oder „Nein“ im Hinblick auf Steuergesetze stimmen. Allerdings bestand zwischen den zwei Kammern Streit darüber, inwieweit die Rechte der 1. Kammer eingeschränkt waren, denn $\ 181$ der Verfassung bezog sich nur auf die Frage der „Abgaben-Verwilligung“. Gerade bei der Beratung um das Einkommensteuergesetz ging es jedoch um Fragen der Art der Erhebung der Steuer sowie über das Subjekt des Steuerpflichtigen, Gegenstand der Besteuerung, Ausnahmen von der Steuerpflicht etc., so dass sich die Einschränkung des Mitwirkungsrechts der 1. Kammer auch nur auf das jeweilige Finanzgesetz beziehen konnte, welches die Steuern mit dem konkreten Steuersatz für das konkrete Etatjahr bewilligte bzw. nur auf den Akt der Bewilligung als solchen ${ }^{23}$.

Dabei sei erwähnt, dass grundsätzlich die Steuerbewilligung nur für die Zeitdauer des Hauptfinanzetats (drei Jahre) erfolgte. Waren die Steuern in festen Sätzen bestimmt, konnten sie insoweit forterhoben werden, als beide Kammern nicht anders entschieden hatten $(\mathbb{\$} 181$ Verfassung). Das Einkommensteuergesetz von 1903 machte hier insofern eine Ausnahme, als nach seinem Art. 19 der in Art. 18 bestimmte „Einheitssatz der Einkommensteuer“ ohne Zustimmung der 1. Kammer für eine Reihe von Jahren nicht und nach deren Ablauf im Wege des Finanzgesetzes nur im gleichen Verhältnis wie die Summe der übrigen direkten und indirekten Steuern erhöht werden konnte - d.h. der konkrete Steuersatz wurde grundsätzlich entsprechend durch das Finanzgesetz im Zuge eines Faktorenverfahrens bestimmt ${ }^{24}$. $\$ 21$ der Verfassung legte die Steuergerechtigkeit und Steuergleichheit als Staatsbürgerrecht fest ${ }^{25}$.

22 Wilhelm Bazille: Das Staats- und Verwaltungsrecht des Königreichs Württemberg. 1908. S. 328.

${ }^{23}$ Karl Göz: Das Staatsrecht des Königreichs Württembergs. 1904. S. 202 ff., 217 f. - Von Riecke, Steuern (wie Anm. 17) S. 75, 137 und $89 \mathrm{ff}$.

${ }^{24}$ Bazille (wie Anm. 22) S. $329 f$.

${ }^{25}$ Carl V. Fricker: Die Verfassungs-Urkunde für das Königreich Württemberg vom 25. Sept. 1819 mit den offiziellen Auslegungs-Material. 1865. S.171, $191 \mathrm{ff} ., 383 \mathrm{ff}$ - - Deblinger (wie Anm. 17) \$343. - Spoerer (wie Anm. 17) S. 84. - Schremmer, Ertragsteuern (wie Anm. 17) S. 7. - Werner Frotscher/Bodo Pieroth: Verfassungsgeschichte. ${ }^{2}$ 1999. Rn. 267. - Klaus Oechs- 


\section{Vorbilder für die württembergische Einkommensteuer}

Nachdem Preußen eine Vorreiterrolle bei der Einführung der Einkommensteuer auf deutschem Boden zukam, wurde diese aber in der nachnapoleonischen Ära im Jahr 1820 durch eine Klassensteuer ${ }^{26}$ ersetzt, die nur noch Ansätze einer Einkommensteuer aufwies. Im Jahr 1851 führte Preußen sodann eine Klassen- und klassifizierte Einkommensteuer ein ${ }^{27}$. Die Klassen- und klassifizierte Einkommensteuer war als eine Art Kompromisslösung, als eine Mischung zwischen einer Klassensteuer und einer auf die individuellen Einkommensverhältnisse abstellende Einkommensteuer konzipiert. Dabei galt die Klassensteuer bei den niedrigeren Einkunftsgruppen und die klassifizierte Einkommensteuer bei den besser gestellten Steuerpflichtigen. Eine Progression enthielt diese Steuer nicht. Die Einstufung erfolgte nach den äußeren Vermögens- bzw. Leistungsfähigkeitsverhältnissen durch eine Kommission bei der Klassensteuer, und bei der klassifizierten Einkommensteuer hatte die Ermittlung der Bemessungsgrundlage ohne tieferes Eindringen in die Vermögens- und Einkunftsverhältnisse durch eine Einschätzungskommission zu erfolgen. Allerdings sah die Novelle vom 25. Mai $1873^{28}$ bei den unteren Einkommensteuerklassen die Berücksichtigung von Kosten für andauernde Krankheiten, starke Kinderzahl, Verpflichtung zur Unterstützung Angehöriger, Verschuldung und außergewöhnlicher Unglücksfälle vor. Bei der Klassen- wie der klassifizierten Einkommensteuer wurde nunmehr als Bemessungsgrundlage gleichermaßen das Einkommen herangezogen. Es wurde ein steuerfreies Existenzminimum in die Klassensteuer eingeführt, und die Einkommensteuer war nicht mehr auf einen Höchstbetrag gedeckelt ${ }^{29}$.

le: Die steuerlichen Grundrechte in der jüngeren deutschen Verfassungsgeschichte. 1993. S.46ff. - Von Sarwey (wie Anm.17) S.179f. - entsprechende Bestimmungen enthielt mit

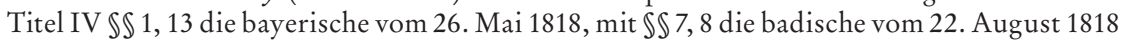
mit Art. 18 und 30 die großherzoglich hessische und mit Art. 4 und Art. 101 die preußische Verfassung vom 31. Januar 1850.

${ }_{26}$ Gesetz vom 30. Mai 1820. Gesetz-Sammlung (wie Anm. 3) 1820. S. 140.

27 Gesetz vom 1. Mai 1851. Gesetz-Sammlung (wie Anm. 3) 1851. S. 193.

${ }^{28}$ Gesetz-Sammlung (wie Anm. 3) 1873. S. 213.

${ }^{29}$ Helferich: Die Reform der direkten Steuern in Bayern. In: Zeitschrift für die gesamte Staatswissenschaft (1873) S. 541-602, 588f., 599. - Walter Mathiak: Was von einem großen Plan blieb: Die preußische klassifizierte Einkommensteuer von 1851. In: Steuer und Wirtschaft (2001) S. 324-340. - Walter Mathiak: Die Einkommensteuer in Preußen im 19. Jahrhundert. In: Finanz-Rundschau (2007) S. 544-550. - Walter Mathiak: Die erste Einkommensteuer in Deutschland: Das Reglement vom 23.2. 1808 für Ostpreußen. In: Steuer und Wirtschaft (1995) S. 352-365. - Alfons Pobl: Von der Einkommensteuer zur Deklarationsberatung. In: Finanz-Rundschau (1979) S. 441-450. - Spoerer (wie Anm. 17) S.56ff. und 68. Carl-Heinz Hener: Karl Freiherr vom Stein als Wegbereiter des deutschen Einkommensteuerrechts. 1988. S. 7-27. - Rosemarie Siegert: Steuerpolitik und Gesellschaft - Vergleichende Untersuchungen zu Preußen und Baden 1815-1848. 2001. S. 89 f., $113 \mathrm{ff} ., 134 \mathrm{ff} ., 392 \mathrm{ff}$. Hans-Ulrich Webler: Deutsche Gesellschaftsgeschichte 1815-1845/49. ${ }^{5} 2008$. S. 377 f. - Ders. Deutsche Gesellschaftsgeschichte 1700-1815. 52008. S. $432 \mathrm{ff}$ - Andreas Thier: Steuergesetz- 
Motor der weiteren Entwicklung der Einkommensteuer war nach dem Gründerkrach von 1873 aufgrund seiner weit vorangeschrittenen industriellen Entwicklung aber sodann nicht Preußen, sondern das Königreich Sachsen. Mit Gesetz vom 22. Dezember $1874^{30}$ hatte Sachsen sich ein modernes Einkommensteuergesetz gegeben, das für andere Staaten, insbesondere Preußen, Vorbildfunktion hatte ${ }^{31}$. Die persönliche Leistungsfähigkeit wurde hier hinreichend berücksichtigt, und es existierte ein progressiver Steuersatz, wobei sich die konkrete Steuerzahllast mittels eines Multiplikators ergab, der durch das Finanzgesetz bestimmt wurde. Erfasst wurden als Einkunftsquellen die Einkünfte aus Nutzungen eines Grundstücks, also Vermietung und Verpachtung mit Land- und Forstwirtschaft auf eigenem Grundstück, Kapitaleinkünfte, Einkünfte aus nichtselbständiger Arbeit, sowie Einkünfte aus Handels- und Gewerbebetrieb einschließlich der Einkünfte aus Land- und Forstwirtschaft, wenn das genutzte Grundstück gepachtet war. Dabei galt hinsichtlich der Gewinnermittlung für Handels- und Gewerbebetriebe der Maßgeblichkeitsgrundsatz der Handels- für die Steuerbilanz ${ }^{32}$. Erfasst wurden von der Einkommensteuer nicht nur natürliche, sondern auch juristische Personen. Das Einkommensteuergesetz vom 2. Juli $1878^{33}$ beließ sodann ein steuerfreies Existenzminimum von $300 \mathrm{M}$. im Jahr ${ }^{34}$. In den Folgejahren wurde das Gesetz novelliert, insbesondere wurden wegen der Idee der Besteuerung nach der Leistungsfähigkeit die untersten Einkommensschichten weitergehend von der Steuer freigestellt und kinderreiche Familien entlastet ${ }^{35}$. Als das württembergische Einkommensteuergesetz von 1903 abschließend beraten wurde, lag das sächsische Einkommensteuergesetz in der Fassung vom 23. Juli 1900 vor $^{36}$.

Insbesondere das bayerische Einkommensteuergesetz vom 19. Mai $1881^{37}$ war, wie erwähnt, auch am Anfang der Diskussion in Württemberg als Modell zu wür-

gebung und Verfassung in der konstitutionellen Monarchie - Staatssteuerreformen in PreuBen 1871-1893. 1999. S. 91-128.

30 Gesetz- und Verordnungsblatt für das Königreich Sachsen. 1874. S. 471.

31 Großfeld (wie Anm. 2) S. 44. - Schremmer, Einkommensteuer (wie Anm. 17) S. 191-214, 196.

32 Walter Mathiak: Das sächsische Einkommensteuergesetz - Entstehung und Durchführung, Genese des Maßgeblichkeitsgrundsatzes. 2005. S. 81. - Heinrich Weber-Grellet: Bilanzsteuerrecht. ${ }^{9}$ 2008. S. 39.

33 Verordnungsblatt (wie Anm. 30) 1878. S. 129.

${ }^{34} \mathrm{Im}$ Änderungsgesetz vom 10.3. 1894 war das Existenzminimum bis $400 \mathrm{M}$. freigestellt - vgl. Dieter Dziadkowski: 120 Jahre Einkommensteuer und 100 Jahre Freistellung des Existenzminimums in Sachsen - Vorbild für die geplante Tarifreform 1996. In: Finanz-Rundschau (1995) S. 46-49, 46.

${ }_{35}$ Metzger/Weingarten (wie Anm. 17) S.49ff. - Zum sächsischen Einkommensteuergesetz vom 10.3. 1894 - Verordnungsblatt (wie Anm. 30) 1894. S. 53. - Vgl. Georg Schanz: Die Novelle zum sächsischen Einkommensteuergesetz vom 2. Juli 1878. In: Finanzarchiv 12 (1895) S. 751-762.

36 Verordnungsblatt (wie Anm. 30) 1900. S. 549, 562.

37 Gesetz- und Verordnungsblatt für das Königreich Bayern. 1881. S. 441. 
digen. Erfasst von der Einkommensteuer wurden nur bestimmte Einkünfte, beispielsweise Einkünfte aus Lohnarbeit, soweit keine längerfristiges Anstellungsverhältnis bestand, wissenschaftlicher, künstlerischer, unterrichtender Tätigkeit sowie freiberuflicher Arbeit, so dass es sich gerade um keine allgemeine Einkommensteuer, sondern eine Art modifizierte Ertragsteuer handelte. Sozial schwach gestellte Personengruppen, wie Witwen mit geringen Einkünften, waren von Gesetzes wegen von der Einkommensteuer freigestellt. Auch wenn der Steuersatz nicht einheitlich war, wies er nur in die Richtung einer Progression. Besteuert wurde die durchschnittliche jährliche Ertragsfähigkeit, da die Steuer für fünf Jahre erhoben wurde. Es bestand Steuererklärungspflicht. Beim Besteuerungsverfahren waren die Gemeinden eingebunden, entsprechend alten Forderungen aus der Revolutionszeit von 1848/49. Es folgte sodann das Einkommensteuergesetz vom 9. Juni $1899^{38}$ und vom 14. August $1910^{39}$.

In Baden, dessen Einkommensteuer näher in Württemberg untersucht wurde, folgte man dem sächsischen Vorstoß mit dem Einkommensteuergesetz vom 20. Juni $1884^{40}$, wobei man ähnlich der Rechtslage in Sachsen vier Haupteinkunftsquellen festlegte und sowohl natürliche wie juristische Personen von der Steuer erfasst waren. Zu den Einkünften gehörte auch die Erlangung geldwerter Vorteile. Die persönliche Leistungsfähigkeit wurde durch die Abziehbarkeit von beruflichen Aufwendungen und die Freistellung des Existenzminimums in Höhe von jährlich 500 M. berücksichtigt. Es bestand letztlich ein progressiver Einkommensteuerstufentarif, der sich jedoch in der genauen Höhe erst aus dem jeweiligen Finanzgesetz ergab. Ähnlich der bayerischen Regelung waren die Gemeinden in das Besteuerungsverfahren eingebunden. Dabei erfolgten in den nächsten Jahren noch einige Änderungen, so wurde durch Gesetz vom 9. August $1900^{41}$ insbesondere das steuerfreie Existenzminimum auf 900 M. angehoben und Eheleute wurden grundsätzlich zusammen veranlagt ${ }^{42}$.

Nachdem Sachsen und andere deutsche Staaten die Einkommensteuer forciert hatten, nahm man sich auch in Preußen wieder der Einkommensteuer an, was, wie erwähnt, auch genaue Beobachtung in Württemberg fand. Im Zuge der Miquel'schen Steuerreform - benannt nach dem preußischen Finanzminister und Nationalliberalen Johannes Franz von Miquel - folgte sodann das preußische Einkommensteuergesetz vom 24. Juni $1891^{43}$. Wie in Sachsen waren von der Einkommensteuer sowohl natürliche wie auch juristische Personen erfasst, wobei sich aber die

38 Verordnungsblatt (wie Anm. 37) 1899. S. 227. - Vgl. Georg Schanz: Die Frage der Steuerreform in Bayern. In: Finanzarchiv 17 (1900) S. 527-550. - Georg Schanz: Das bayerische Ertragsteuersystem und seine Entwicklung. In: Finanzarchiv 17 (1900) S. 551-772.

39 Verordnungsblatt (wie Anm. 37) 1910. S. 493.

40 Großherzoglich Badisches Regierungs-Blatt 1884. S. 321.

41 Regierungs-Blatt (wie Anm. 40) 1900. S. 877, 991 und XLVI.

42 Karl Stiefel: Baden 1648 bis 1952. ${ }^{2} 1979$. S. 826. - Buchenberg: Die Steuerreform im Grossherzogtum Baden. In: Finanzarchiv 18 (1901) S. 1-45, 43 ff.

43 Gesetz-Sammlung (wie Anm. 3) 1891. S. 175. 
Besteuerung auf die Gewinnausschüttung bezog. Das Existenzminimum von 900 M. im Jahr war freigestellt. Besteuert wurde entsprechend der Quellentheorie nur das Einkommen, welches aus vier Quellen stammte. Hiernach wurden Einkünfte aus Kapitalvermögen, Grundvermögen bzw. Vermietung und Verpachtung aber auch Einkünfte aus Land- und Forstwirtschaft, Gewerbebetrieb sowie sonstiger gewinnbringender Tätigkeit, worunter sowohl Einkünfte aus selbständiger wie nichtselbständiger Arbeit als auch Pensionen, aber grundsätzlich nicht private Vermögensveräußerungen fielen, besteuert. Wie in Sachsen bestand grundsätzlich das Maßgeblichkeitsprinzip der Handels- für die Steuerbilanz. Berufliche Aufwendungen und gewisse existenzsichernde Ausgaben bzw. außergewöhnliche Belastungen wurden im Zuge des Leistungsfähigkeitsprinzips steuerreduzierend beachtet. Wie in anderen Einkommensteuergesetzen dieser Zeit, wurde das Einkommen im Voraus bestimmt, wobei hinsichtlich schwankender Einnahmen ein Durchschnittswert der letzten drei Jahre anzusetzen war. Traditionell waren nur erhebliche nachträgliche Einkommensveränderungen, d.h. Minderungen von mehr als einem Viertel, berücksichtigungsfähig. Es galt ein progressiver Steuersatz. Bei der Einkommensteuer handelte es sich um eine Jahressteuer, bei der Vorauszahlungen zu erbringen waren. Die Kommunen waren wiederum in die Steuerverwaltung eingebunden ${ }^{44}$.

Auch das Großherzogtum Hessen besaß die Einkommensteuer, die in Württemberg mit bei der Suche nach der besten Regelung herangezogen wurde, so erging das Einkommensteuergesetz vom 21. Juni $1869^{45}$, welches das Einkommensteuergesetz vom 16. Dezember $1868^{46}$ modifizierte. Dabei folgte die Besteuerung ähnlich dem preußischen Gesetz von 1851 in zwei Abteilungen. Das Gesetz erfuhr in der Folgezeit weitere Veränderungen. Bei den abschließenden Beratungen in Württemberg lag das hessische Einkommensteuergesetz vom 18. August $1899^{47}$ als Vergleichsmaterial vor. Wie in Preußen wurden auch Kapitalgesellschaften der Einkommensteuer hinsichtlich der Dividenden bzw. Gewinnausschüttungen, welche sie gegenüber ihren Anteilseignern tätigten, unterworfen. Ehegatten wurden grundsätzlich zusammen veranlagt. Die Ermittlung des zu versteuernden Einkommens erfolgte wiederum im Vorhinein. Nachträgliche Änderungen waren bei den Einkommensverhältnissen wie in den anderen deutschen Staaten nur beachtlich, wenn sie zu einer Einkommensminderung von mehr als einem Viertel führten. Die

${ }^{44}$ Arthur Neubrand: Die Belastung mit direkten Staatssteuern in Preussen, Bayern, Sachsen, Württemberg und Baden. In: Finanzarchiv 33 (1916) S. 702-720. - Thier (wie Anm. 29) S. 446-487, 632. - Thorsten Kassner: Der Steuerreformer Johannes von Miquel - Leben und Werk. Zum 100. Todestag des preußischen Finanzministers. Ein Beitrag zur Entwicklung des Steuerrechts. 2001. S. 89 ff. - Metzger/Weingarten (wie Anm. 17) S. 33 ff. - Klaus F. Pobl: Die Entwicklung des ertragsteuerlichen Maßgeblichkeitsprinzips. 1983. S. 47 ff. - Gehm (wie Anm. 17).

${ }^{45}$ Großherzoglich Hessisches Regierungsblatt 1869. S. 433.

46 Regierungsblatt (wie Anm. 45) 1868. S. 1305.

${ }_{47}$ Regierungsblatt (wie Anm. 45) 1899. S. 461, 471. 
Einkommensteuer wurde weiterhin in zwei Abteilungen progressiv erhoben, wobei sich der konkrete Steuersatz aus dem Finanzgesetz ergab. Entsprechend dem Leistungsfähigkeitsprinzip waren berufliche Aufwendungen steuerlich zu berücksichtigen. Das steuerfreie Existenzminimum lag im Jahr bei 500 M., die Kommunen waren wiederum ins Besteuerungsverfahren eingebunden ${ }^{48}$.

Vor Ausbruch des Ersten Weltkrieges hatten alle deutschen Bundesstaaten Einkommensteuergesetze, zuletzt führten die Großherzogtümer Mecklenburg-Schwerin und Mecklenburg-Strelitz im Jahr 1913 die Einkommensteuer ein ${ }^{49}$.

\section{Die Regelungen des württembergischen Einkommensteuergesetzes von 1903}

Das Einkommensteuergesetz war mit insgesamt 83 Artikeln sehr umfangreich. Zielsetzung war, die Staatseinnahmen zu sichern, ohne die sozial schwächer gestellten Steuerbürger zu sehr zu belasten ${ }^{50}$. Ergänzt wurde das Gesetz durch die Verfügung des Finanzministeriums, betreffend den Vollzug des Gesetzes vom 8. August 1903 über die Einkommensteuer vom 9. Juni 1904 ${ }^{51}$.

In Anlehnung an das preußische Gesetz von 1891 wurden vier Einkunftsquellen besteuert ${ }^{52}$. Dies waren neben den erwähnten Spekulationsgewinnen die weiteren in Art. 6, Art. 7 Abs. 2 und in den Art. 12 bis 17 näher erläuterten Einkunftsquellen:

- Einkommen aus Grundstücken, Gefällen und Gebäuden einschließlich des Mietwertes der Wohnung im eigenen Haus ${ }^{53}$, sowie aus dem Betrieb von Landund Forstwirtschaft (Art. 6 Nr. 1 und Art. 12),

- Einkommen aus dem Betrieb eines Gewerbes einschließlich Handel und Bergbau sowie aufgrund gewohnheitsmäßig ausgeübter Tätigkeit erwirtschaftete Spekulationsgewinne (Art 6 Nr. 2 und Art. 13),

- Einkommen aus Kapitalien und Renten (Art. 6 Nr. 3 und Art. 14),

${ }^{48}$ C. Glässing: Die Neugestaltung der direkten Staatsbesteuerung im Großherzogtum Hessen (1899). In: Finanzarchiv 17 (1900) S. 178-360, 274 ff.

${ }^{49}$ Heinrich Wilhelm Kruse: Not und Feuer, Krieg und Steuer - Ein Beitrag über die Entwicklung von Steuern. In: Steuer und Wirtschaft (1998) S. 3-14, 6.

50 Dehlinger (wie Anm. 17) $\$ 379$.

${ }^{51}$ Regierungsblatt (wie Anm. 5) 1904. S. 117.

52 Denkschrift (wie Anm. 17) S. 400. - Pistorius (wie Anm. 8) S. 67 ff. - Göz (wie Anm. 21) S. 77, 85 ff. - Hermann Müller: Das Württembergische Einkommensteuergesetz vom 8. August 1903. 1909. S. 23.

53 Müller (wie Anm. 52) S. 19 - abgestellt wurde auf den Verkaufswert und hiervon ein Zins in Höhe von $4 \%$ der Steuer unterworfen. 
- Einkommen aus Dienst- und Arbeitsverhältnissen, aus wissenschaftlichen und künstlerischen Berufen, aus sonstigen gewinnbringenden Beschäftigungen, aus wiederkehrenden Bezügen und sonstigen Vorteilen (Art. 6 Nr. 4 und Art. 15) ${ }^{54}$. Unter Berücksichtigung der vier Quellen wurde der Begriff des Einkommens in Württemberg nach Göz „als der Geldwert der sämtlichen Sachgüter, welche in einem Jahr dem Steuerpflichtigen als die reinen Erträge dauernder Quellen der Gütererzeugung zur freien Verfügung verbleiben“, bestimmt ${ }^{55}$.

Zum Einkommen gehörten in Anlehnung an die badische Einkommensteuer auch geldwerte Vorteile, welche gemäß Art. 6 Abs. 2 nach dem örtlichen Mittelwert $\mathrm{zu}$ veranschlagen waren.

Das Gesetz machte keinen Unterschied zwischen natürlichen Personen und $\mathrm{Ka}$ pitalgesellschaften, Stiftungen sowie Genossenschaften bzw. Personenvereinen mit nicht geschlossener Mitgliederzahl ${ }^{56}$ unabhängig von ihrer Rechtsfähigkeit, die unbeschränkt einkommensteuerpflichtig in Württemberg waren, wenn sie dort ihren Sitz hatten (Art. 2) ${ }^{57}$ und folgte somit in weiten Teilen dem sächsischen Einkommensteuergesetz sowie der württembergischen Steuerrechtstradition ${ }^{58}$. Art. 1 enthielt eine diffizile Regelung zur unbeschränkten persönlichen Steuerpflicht natürlicher Personen. Danach waren alle württembergischen Staatsbürger erfasst und Angehörige des Reiches, die länger als ein Jahr ihren Wohnsitz bzw. ohne Wohnsitz im sonstigen Reichsgebiet zu haben, ihren Aufenthalt in Württemberg hatten, oder Ausländer, die länger als ein Jahr ihren Aufenthalt in Württemberg hatten ${ }^{59}$. (Beschränkt) steuerpflichtig waren nach Art. 3 ohne Rücksicht auf Staatsangehörigkeit, Wohnsitz oder Aufenthaltsort alle Personen mit Einkommen aus in Württemberg gelegenem Grund- und Gebäudebesitz und dort betriebenem Gewerbe, sowie aus der württembergischen Staatskasse bezahlten Besoldungen, Wartegeldern, Ruhegehalten, Pensionen und Unterstützungen bzw. sonst gewinnbringender Beschäftigungen ${ }^{60}$.

Nach Art. 5 und Art. 18 waren Jahreseinkommen wie in Hessen bis 500 M. grundsätzlich steuerfrei. Diese Regelung galt nicht für juristische Personen. Dabei wurde für diese Grenze nur das in Württemberg erzielte Jahreseinkommen - also nach Abzug der beruflichen Aufwendungen - herangezogen. Ein steuerfreies Existenzminimum im heutigen Sinn war dies aber wie bei früheren Regelungen

54 Metzger/Weingarten (wie Anm. 17) S. 64.

55 Göz (wie Anm.21) S. 72 ff., 75.

56 Die Erfassung dieser Personenvereine war eine württembergische Besonderheit - vgl. Pistorius (wie Anm. 8) S. 56.

57 Bazille (wie Anm. 22) S. 331. - Göz (wie Anm. 23) S. 205 f. - Ders. (wie Anm. 21) S. $41 \mathrm{ff}$. - Metzger/Weingarten (wie Anm.17) S.63f.

58 Denkschrift (wie Anm. 17) S. 400.

59 Bazille (wie Anm. 22) S.330f. - Robert Fette: Das württembergische Einkommensteuergesetz. ${ }^{3}$ 1912. S. 2. - Metzger/Weingarten (wie Anm. 17) S. 63. - Göz (wie Anm. 23) S. 206.

${ }_{60}$ Metzger/Weingarten (wie Anm.17) S.64. - Bazille (wie Anm.22) S.331. - Göz (wie Anm.23) S. 206. 
nicht, da bei Überschreitung dieser Freigrenze von der ersten Mark ab Steuern zu bezahlen waren.

Steuerpflichtig war gemäß Art. 9 nur das reine Jahreseinkommen - also im Unterschied zu den Ertragsteuern wiederum nach Abzug der beruflichen Aufwendungen - nach dem Stand bei Beginn des Rechnungsjahres ${ }^{61}$. Art. 9 I. Nr. 1 regelte fast wortgleich der heutigen Regelung den Begriff der Werbungskosten bzw. Betriebsausgaben: „Bei der Ermittlung des steuerbaren Einkommens (...) sind von den Einnahmen in Abzug zu bringen: die zur Erwerbung, Sicherung und Erhaltung des Einkommens verwendeten Ausgaben (...)“. Bei Aktiengesellschaften wurden im Hinblick auf die Gewinnermittlung auch zusätzlich zumindest teilweise die Ausschüttungen an die Aktionäre mindernd berücksichtigt (Art. 16 Abs.3). Bei dieser Entlastungsregelung spielten auch Gründe der Förderung der württembergischen Industrie eine Rolle, wollte man doch das diesbezügliche Wachstum nicht hemmen - so war die Anzahl der Aktiengesellschaften, die 1883 insgesamt 84 zählten, 1892 bereits auf 136 angestiegen und schließlich um 1904 auf etwa 200 angewachsen $^{62}$.

Bei der Berechnung des zu versteuernden Einkommens waren die von Gemeinden und Amtskörperschaften erhobenen Ertrag- und Einkommensteuern nicht abzugsfähig (Art. 9 II. Nr. 1, 2 und 4) ${ }^{63}$, jedoch nach Art. 9 I. Nr. 3 die staatlichen Kapital- und Ertragsteuern ${ }^{64}$.

Die Absetzung für Abnutzung wurde ähnlich den heutigen Bestimmungen eigens in Art. 9 I. Nr. 2 geregelt ${ }^{65}$. Dabei waren nach $\ 4$ Nr. 2 der Verfügung grundsätzlich nur die regelmäßigen jährlichen Abnutzungen absetzbar.

Eine Unterscheidung zwischen Werbungskosten, bzw. Betriebsausgaben einerseits und Sonderausgaben andererseits wurde wie im preußischen Gesetz von 1891 nicht gemacht, da Art. 9 I Nr. 5 Sozialaufwendungen wie Beiträge zur Krankenund Unfallversicherung gleich den heutigen Betriebsausgaben bzw. Werbungskosten behandelte.

Wie heute auch noch waren Kosten für Berufskleidung, wenn sich diese von der bürgerlichen unterschied, absetzbar ${ }^{66}$. Auch waren Fahrtkosten zwischen Wohnung und Arbeitsstätte und Verpflegungsmehraufwand seit 1908 nach einer entsprechenden Entscheidung des Finanzministeriums im Hinblick auf einen Arbei-

61 Göz (wie Anm. 23) S. 206.

62 Alfred Deblinger: Die Besteuerung der Aktiengesellschaften in Württemberg. In: Finanzarchiv 22 (1904) S. 499-579, 502, 524 ff., 544 ff., 556 ff. - Pistorius (wie Anm. 8) S. 62 ff. - Müller (wie Anm. 52) S. 135 ff. - Denkschrift (wie Anm. 17) S. 401. - Göz (wie Anm. 21) S. 213 .

63 Göz (wie Anm. 21) S. 74, 112. - Müller (wie Anm. 52) S. 39 f.

64 Fette (wie Anm. 59) S. 5. - Göz (wie Anm. 21) S. 123 f.

65 Göz (wie Anm. 23) S. 206. - Göz (wie Anm. 21) S. $116 \mathrm{ff}$.

66 Fette (wie Anm. 59) S. 5. 
ter, der in Stuttgart-Heslach wohnte und in Obertürkheim beschäftigt war, abziehbar (der Verpflegungsmehraufwand wurde mit jährlich 170 M. bemessen) ${ }^{67}$.

Demgegenüber enthielt Art. 9 II. Nr. 3 eine Regelung, die ähnlich der aktuellen einkommensteuerlichen Regelung Kosten der privaten Lebensführung nicht zum Abzug zuließ $\beta^{68}$. Für gewisse Mischaufwendungen sah aber $\$ 6$ A. III. der Verfügung eine Aufteilung entsprechend der privaten und der beruflichen Veranlassung vor. Entgegen früheren Regelungen war durch $\$ 9$ I Nr. 4 der Schuldzinsenabzug möglich, nicht abziehbar war aber die Schuldtilgung ( $\$ 4$ Nr. 3 der Verfügung). Dabei war die Abzugsfähigkeit der Schuldzinsen unabhängig vom Aufnahmegrund für das entsprechende Darlehen gegeben ${ }^{69}$. Über Art. 9 I Nr. 6 waren Verluste, die bei einer Einkunftsquelle auftraten, im Zuge einer Verlustverrechnung bei Einnahmen aus anderen Einkunftsquellen abziehbar ${ }^{70}$.

Die Einkommensteuer war zwar eine Jahressteuer, sie wurde jedoch gemäß der Rechtstradition bzw. dem badischen und bayerischen resp. preußischen Vorbild entsprechend der Verhältnisse zu Beginn des Steuerjahres quasi futurisch festgesetzt, es sei denn Veränderungen zu diesen Verhältnissen im laufenden Steuerjahr waren hinreichend wahrscheinlich (Art. 10). Wie in Baden war auf die Verhältnisse des 1. Aprils des Steuerjahres gemäß $\$ 5$ Abs. 2 der Verfügung abzustellen, dies entsprach insofern auch der Regelung von Art. 7 der Kapital- und Diensteinkommensteuer von $1852^{71}$. Für landwirtschaftliche Betriebe wie für Gewerbebetriebe galt die Besonderheit, dass Aufwendungen unabhängig vom Zeitpunkt ihrer tatsächlichen finanziellen Belastung nach Art. 12 Nr. 7 resp. Art. 13 Abs. 1 Nr. 2 abziehbar waren ${ }^{72}$. Drastische Änderungen der Einkommensverhältnisse im laufenden Steuerjahr - z.B. Minderung des steuerpflichtigen Einkommens um mehr als ein Viertel - waren nach Art. 66 und 67 ähnlich wie in Preußen und Hessen zu berücksichtigen, in anderen Fällen fand aber keine Anpassung statt ${ }^{73}$. Ansonsten galt aber nach $\$ 5$ I. Nr. 2 der Verfügung, dass bloße Zweifel an der Realisierung gewisser Ansprüche nicht davon befreiten, diese der Besteuerung zu unterwerfen. Bei Kapitaleinkünften galt im Zweifel ein Zins von 4\% als erzielt (Art. 14 Abs. 2) ${ }^{74}$.

Das Einkommen von Ehegatten wurde zusammengerechnet, ebenso wurde grundsätzlich das Einkommen der minderjährigen Kinder, soweit es nicht aus deren eigener Gewerbstätigkeit entstammte, dem Familienoberhaupt zugerechnet, so dass eine ähnliche Regelung wie in Baden bestand (Art. 11 und $\$ 19$ Nr. 1 lit.b der

${ }^{67}$ Fette (wie Anm. 59) S. 8.

${ }^{68}$ Göz (wie Anm. 21) S. 111.

${ }^{69} G \ddot{o z}$ (wie Anm. 21) S. 124.

70 Göz (wie Anm. 23) S. 207.

71 Pistorius (wie Anm. 8) S. 75 ff. - Bazille (wie Anm. 22) S. 331. - Fette (wie Anm. 59) S. 4. - Göz (wie Anm. 21) S. $136 \mathrm{ff}$ - Müller (wie Anm. 52) S. $46 \mathrm{ff}$.

72 Göz (wie Anm. 21) S. 163.

${ }^{73}$ Göz (wie Anm. 21) S. 284ff. - Metzger/Weingarten (wie Anm.17) S. 69.

${ }^{74}$ Göz (wie Anm. 21) S. $184 \mathrm{ff}$. - die Besteuerung richtete sich hier weitgehend am Gesetz vom 19. September 1852 aus. 
Verfügung), wenn auch im Unterschied zu Preußen keine grundsätzliche Besteuerung nach Haushalten erfolgte ${ }^{75}$.

Art. 13 legte ähnlich wie in Preußen und Sachsen für Gewerbetreibende das Maßgeblichkeitsprinzip von Handels- und Steuerbilanz fest ${ }^{76}$. Gewerbetreibende, die nicht nach HGB zur Buchführung verpflichtet waren, ermittelten ähnlich wie heute noch ihren Gewinn durch eine Einnahme-Überschuss-Rechnung ${ }^{77}$. Außerhalb von der Landwirtschaft bzw. vom Gewerbebetrieb bestand für nicht buchführungspflichtige Steuerbürger hinsichtlich der Einnahmen das Zuflussprinzip, d.h. es war auf den jeweiligen Zeitpunkt des Geldzuflusses abzustellen (Art. 15 Abs. 3$)^{78}$. Unter Beachtung von Art. 9 ergab sich mithin hier auch das Abflussprinzip bezüglich der Ausgabenseite.

Es galt für alle Einkunftsarten gleich ein progressiver von ca. 0,3 bis $5 \%$ gehender Steuersatz - „Einheitssatz“ (Art.18, 19). Mit der Tarifspitze von 5\% lag Württemberg im Reich im oberen Bereich. Dabei war ein Stufentarif gegeben. Ab 200.000 M. Jahreseinkommen ging die progressive Steuer in einen linearen Tarif über. Bemessungsgrundlage war das steuerbare Jahreseinkommen, also, wie dargelegt, die Einnahmen nach Abzug der entsprechenden beruflich veranlassten Aufwendungen ${ }^{79}$. Die konkrete Steuerhöhe ergab sich jedoch wie in Hessen und Baden oder im sächsischen Einkommensteuergesetz von 1874 resp. auch dem württembergischen Gesetz von 1852 aus speziellen gesetzlichen Regelungen des jeweiligen Finanzgesetzes, die einen Faktor für den Einheitssatz bestimmten ${ }^{80}$.

Gemäß Art. 19 Abs. 2 war eine Erhöhung des Steuersatzes durch das Finanzgesetz nur zulässig, wenn die Gesamtheit der direkten und indirekten Steuern, mit Ausnahme der Erbschafts- und Schenkungsteuer, sowie der auf Reichsgesetz beruhenden Gerichtsgebühren erhöht wurden, und die Erhöhung der Einheitssätze der Einkommensteuer im richtigen Verhältnis zu der Erhöhung dieser anderen Steuerarten stand. Nach längerem Streit hatte man sich zwischen den Kammern geeinigt, dass hinsichtlich dieser Frage im Finanzgesetz der 1. Kammer das volle Mitwirkungsrecht zustünde, insofern kam der Vorschrift verfassungsrechtliche Bedeutung $\mathrm{zu}^{81}$. Bis 1908 lag der Faktor bei 100\%, 1909/1910 waren es bereits 112\%, 1911 bis 1915 105\% und 1917 erreichte der Satz schließlich in den höheren Einkommen

75 Göz (wie Anm. 21) S. 147 ff.

76 Pistorius (wie Anm. 8) S.69. - Neubrand (wie Anm.44) S.704. - Denkschrift (wie Anm.17) S. $473 \mathrm{ff} .-G \ddot{z z}$ (wie Anm. 21) S. $178 \mathrm{ff}$.

77 Müller (wie Anm. 52) S. $89 \mathrm{ff}$.

78 Göz (wie Anm. 21) S. 199.

79 Göz (wie Anm. 21 S. 74, 222.

80 Göz (wie Anm. 23) S. 207. - Ders. (wie Anm. 21) S. 222 f. - Bazille (wie Anm. 22) S. 331. - Metzger/Weingarten (wie Anm. 17) S.66. - Denkschrift (wie Anm. 17) S. 400. - Pistorius (wie Anm. 8) S. 50. Zu den unterschiedlichen Tarifen in Deutschland jener Zeit vgl. Georg Schanz: Die sächsische Steuerreform vom Jahr 1902. In: Finanzarchiv 20 (1903) S. 234-255, $254 \mathrm{f}$.

81 Göz (wie Anm. 23) S. 204 f. - Ders. (wie Anm. 21) S. 223 f. - Müller (wie Anm. 52) S. 146. 
einen Faktor von $130 \%{ }^{82}$. Man war sich von Seiten der Regierung und der Stände von Anfang an einig, dass der Tarif den unteren Einkommen mindestens diejenigen Erleichterungen bringen müsse, die der Tarif der Dienst- und Berufseinkommensteuer den Dienst- und Berufseinkommensteuerpflichtigen seither schon gewährt hatte.

Uneinig war man sich aber über die näheren Fragen der weiteren Ausgestaltung $^{83}$. Für verheiratete, geschiedene oder verwitwete Steuerpflichtige sowie kinderreiche Familien mit einem steuerbaren Jahreseinkommen bis 2.000 bzw. 3.200 M. wurde Tarifermäßigung durch Einordnung in eine geringere Einkommensstufe gewährt (Art.20). Bei Steuerpflichtigen mit einem steuerbaren Jahreseinkommen bis $5.000 \mathrm{M}$. waren außergewöhnliche Belastungen - ansatzweise den heutigen außergewöhnlichen Belastungen vergleichbar, jedoch wiederum nur tarifermäßigend - auf Antrag zu berücksichtigen (Art. 21 bzw. $\$ 14$ der Verfügung). Dabei trat die Ermäßigung nach Art. 20 zu der nach Art. 21 hinzu, so dass sich eine SteuerermäBigung bis zu fünf Stufen und folglich ein Freibetrag von bis zu 1.250 M. ergeben konnte ${ }^{84}$. Die Entscheidung darüber, ob und in welcher Höhe die Steuerermäßigung zu gewähren war, fällte die Einschätzungskommission aufgrund freier Beweiswürdigung nach eigenem Ermessen ${ }^{85}$.

Art. 44 ff. regelte die Steuererklärung bzw. deren genauen Inhalt. Erklärungspflichtig waren ähnlich wie in Preußen bzw. wie in Hessen grundsätzlich nur Steuerpflichtige mit einem steuerbaren Einkommen ab 2.600 M. im Jahr, denen das Bezirkssteueramt eine entsprechende Aufforderung mit den diesbezüglichen Steuerformularen zusandte (Art. 44) ${ }^{86}$. Darüber hinaus waren Kapitalgesellschaften unabhängig von der Einkommenshöhe erklärungspflichtig. Die Vordrucke enthielten entsprechende Anleitungen zum Ausfüllen der Erklärungsformulare, dem Steuerpflichtigen war es unbenommen, die Formulare durch eigenen Anlagen zu ergänzen ( $\int 19$ Nr.3 der Verfügung). Es gab zwei verschiedene Formulare für natürliche Personen und für Kapitalgesellschaften (Anlage 2 und 3 der Verfügung). Neben der Anleitung zur Ausfüllung enthielten die Formulare insbesondere Rechtsbehelfsbelehrungen und Hinweise auf die steuerrechtlichen Strafvorschriften. Die Frist für die Abgabe der Steuererklärung betrug nach $\ 18$ Nr. 2 der Verfügung grundsätzlich 21 Tage ab entsprechender Aufforderung. Den näheren Inhalt der Steuererklärung legte Art. 46 fest, wonach die gesamten einkommensrelevanten Besteuerungsgrundlagen anzugeben waren und bei der schriftlich eingereichten Erklärung diese gemäß Art. 45 Abs. 1 S. 2 eigenhändig vom Steuerpflichtigen zu unterzeichnen war. Der Steuerpflichtige musste in seiner Erklärung versichern, dass er wahrheitsgemäße Angaben gemacht hatte (Art. 45 Abs. 2). Die Steuererklä-

\footnotetext{
82 Metzger/Weingarten (wie Anm.17) S. 66.

83 Denkschrift (wie Anm. 17) S. 400.

${ }^{84}$ Metzger/Weingarten (wie Anm. 17) S. 66f. - Göz (wie Anm. 21) S. $225 \mathrm{ff}$.

${ }^{85}$ Fette (wie Anm. 59) S. $11 \mathrm{f}$.

86 Metzger/Weingarten (wie Anm. 17) S.67.
} 
rung war nach dem vorgeschriebenen Formular schriftlich oder zu Protokoll beim Bezirksteueramt oder der Wohnsitzgemeinde mit der Versicherung der Wahrheitsmäßigkeit der Angaben abzugeben (Art.45). Steuerpflichtigen mit einem geringeren Jahreseinkommen als 2.600 M. war es unbenommen, freiwillig entsprechende Steuererklärungen abzugeben ( $\ 18$ Nr. 2 der Verfügung). Außerdem konnte bei Zweifeln hinsichtlich der Einkommensverhältnisse auch von diesen Personen eine Erklärung eingefordert werde (Art. 44 Abs. 3).

Das Steuerkollegium als dem Finanzministerium nachgeordnete Mittelbehörde hatte die obere Leitung, wobei die unmittelbare Leitung des Einschätzungsverfahrens dem Vorstand des Bezirkssteueramtes als Vorsitzenden der Einschätzungskommission oblag (Art. 23) ${ }^{87}$. Die Gemeinden waren bei der Steuerveranlagung, die nur in der Ermittlung des steuerpflichtigen Einkommens bestand, in Form der Bestellung von Personen (Ortsschätzern), die Mitglieder der Einschätzungskommission waren, eingebunden (Art. 24 ff.). Zusätzlich wirkten vom Steuerkollegium bestellte Personen (Bezirksschätzer) mit. Die Veranlagung bzw. Einschätzung zur Einkommensteuer wurde am Wohnsitz des Steuerpflichtigen bzw. am Sitz der juristischen Person nach Art. 38 vorgenommen. Art. 53 legte vergleichbar heutigen Regelungen dem Steuerpflichtigen Mitwirkungspflichten auf. Grundsätzlich war den Angaben des Steuerpflichtigen, ähnlich wie heute, aber Glauben zu schenken (Art.54). Sodann legte die Einschätzungskommission das zu versteuernde Einkommen der Höhe nach aufgrund einer Einschätzung fest (Art.52). Seine Entscheidung traf dabei die Einschätzungskommission durch Abstimmung, wobei grundsätzlich die einfache Mehrheit der Kommissionsmitglieder ausschlaggebend war (Art. 32). Das Ergebnis der Veranlagung war in eine Einkommensteuerliste einzutragen (Art. 55) und dem Steuerpflichtigen mit Rechtsbehelfsbelehrung bekannt zu geben (Art. 56) ${ }^{88}$.

Gegen das Gesamtergebnis der Steuereinschätzung war sowohl dem Steuerpflichtigen, wie dem Vorsitzenden der Einschätzungskommission die Beschwerde als Rechtsmittel innerhalb einer Zweiwochenfrist gegeben. Gegen die Entscheidung des Steuerkollegiums konnten sowohl der Steuerpflichtige als auch der Vorsitzende des Steuerkollegiums wiederum binnen Zweiwochenfrist eine weitere Beschwerde beim Finanzministerium einreichen (Art. 62).

Wendete sich der Steuerpflichtige gegen eine Schätzung, so war er beweisbelastet, dass diese fehlerhaft war. Nach Art. 64 war das Finanzministerium in Württemberg nicht als letzte Rechtsmittelinstanz vorgesehen, vielmehr war es eine zusätzliche Instanz. Zwischen der Beschwerde (Berufung) an das Steuerkollegium und der Rechtsbeschwerde an den Verwaltungsgerichtshof war somit noch eine weitere Beschwerde an das Finanzministerium gegeben. Damit konnte der Verwaltungsgerichtshof auch über die Rechtmäßigkeit der Entscheidung des Finanzminis-

87 Göz (wie Anm. 23) S. 223. - Bazille (wie Anm. 22) S. 326. - Göz (wie Anm. 21) S. 232.

88 Metzger/Weingarten (wie Anm. 17) S. 68. - Göz (wie Anm. 21) S. 230 f., 257 ff. 
teriums auf Anrufung des Steuerpflichtigen binnen Zweiwochenfrist entschei$\operatorname{den}^{89}$. Steuerpflichtige, welche auch auf Mahnung ihrer Verpflichtung zur Abgabe einer Steuererklärung nicht nachgekommen waren und daher die gesamten Besteuerungsgrundlagen geschätzt werden mussten, verloren ihr Recht auf Beschwerdeeinlegung (Art. 49) ${ }^{90}$.

An die Steuerveranlagung aufgrund Einschätzung schloss sich dann die Steuererhebung an (Art. $76 \mathrm{ff}$.). Rechtsmittel hatten wie heute auch noch keine aufschiebende Wirkung, was die Verpflichtung zur Steuerentrichtung anbelangt (Art. 78$)^{91}$. Aus Billigkeitsgründen konnte von einer Durchsetzung des Steueranspruchs abgesehen werden (Art. 79) ${ }^{92}$.

Wie in vielen anderen deutschen Steuergesetzen - so beispielsweise im badischen oder bayerischen resp. preußischen Einkommensteuergesetz - und auch entsprechend der württembergischen Rechtstradition, wurden wissentlich begangene Steuerverfehlungen mit der Absicht der Steuerverkürzung entsprechend dem Multiplarystem ${ }^{93}$ mit einem Vielfachen des Verkürzungsbetrages bestraft - dem sieben- bis zehnfachen Betrag der hinterzogenen Steuer (Art. 70). Davon unberührt blieb die Verpflichtung, die verkürzte Steuer selbst nach zu entrichten (Art. 72). Bei unbeabsichtigtem Handeln war eine Ahndung von einer bis 300 M. vorgesehen. Sowohl im Hinblick auf die Tat nach Art. 70 als auch nach Art. 71 war der Verschuldensnachweis erforderlich, da es sich um echte Kriminalstrafen bzw. kriminelle Ordnungsstrafe handelte. Dabei bestand die Möglichkeit, durch Selbstanzeige Straffreiheit zu erlangen (Art.73). Für die Steuerstrafrechtspflege waren in erster Instanz die Bezirks- und Lokalbehörden des Finanzdepartements resp. die Kameralämter zuständig ${ }^{94}$.

Nach diesen Vorschriften wurde die Einkommensteuer in Württemberg erstmals im Jahr 1905 erhoben (Art. 83) ${ }^{95}$. Abgesehen von der Änderung des Steuermultiplikators in den Finanzgesetzen erfuhr die württembergische Einkommensteuer bis zum Ersten Weltkrieg keine Modifikationen.

Die Ertragsteuern auf Grund, Gebäude, Gewerbe und Kapital wurden weiterhin neben der Einkommensteuer als Ergänzungssteuern erhoben ${ }^{96}$, indem sie an Tat-

${ }^{89}$ Helmut Cordes: Untersuchungen über Grundlagen und Entstehung der Reichsabgabenordnung vom 23. Dezember 1919. 1971. S. 94. - Bazille (wie Anm. 22) S. 332. - Metzger/ Weingarten (wie Anm. 17) S. 68. - Göz (wie Anm. 23) S. 207. - Ders. (wie Anm. 21) S. 266 ff. - Müller (wie Anm. 52) S. 278 ff. - Pistorius (wie Anm. 8) S. 82.

90 Metzger/Weingarten (wie Anm. 17) S. 67.

91 Göz (wie Anm.21) S. 312.

92 Göz (wie Anm. 21) S. 312.

93 Matthias Gehm: Die steuerstrafrechtlichen Bestimmungen in der Reichsabgabenordnung vom 13. Dezember 1919. 2010. S. $10 \mathrm{ff}$.

${ }_{94}$ Göz (wie Anm.23) S.225f. - Deblinger (wie Anm. 17) \$344. - Bazille (wie Anm. 22) S. $326 \mathrm{f}$.

95 Metzger/Weingarten (wie Anm. 17) S. 69.

${ }^{96}$ Gesetz, betreffend Abänderungen des Gesetzes vom 28. April 1873 über die Grund-, 
bestände anknüpften, welche von der Einkommensteuer nicht oder nur ungenügend erfasst wurden. Dies erklärte sich daraus, dass nach damaliger Vorstellung das sog. fundierte Einkommen stärker als das unfundierte zu belasten war ${ }^{97}$, wobei es gerade durch die Kapitalsteuer das Fehlen einer Vermögensteuer in Württemberg auszugleichen galt ${ }^{98}$. So waren die Erträge, welche auch Art. 14 des Einkommensteuergesetzes erfasst, zusätzlich mit der Kapitalsteuer ${ }^{99}$ belegt. Die bisherige Dienst- und Berufseinkommensteuer ging in der Einkommensteuer auf ${ }^{100}$. Der Steuersatz konnte aber bei den Ertragsteuern nach Einführung der Einkommensteuer ermäßigt werden, wurden sie doch gegenüber der Einkommensteuer zu Ergänzungsabgaben - vgl. insofern Art. 107 des Grund-, Gebäude- und Gewerbesteuer von $1903^{101}$.

\section{Die parlamentarische Debatte um die Einkommensteuer}

Hier soll von dem langen parlamentarischen Entstehungsprozess, der wie dargestellt bereits im Jahr 1889 begann, nur jener Abschnitt näher beleuchtet werden, als nach dem ersten Scheitern das Finanzministerium unter von Zeyer am 30. April 1901 einen neuen Gesetzesentwurf der Abgeordnetenkammer vorlegte ${ }^{102}$. Die Progression fand bei diesem Entwurf mit einem Einheitssatz von 4,5\% ihre Begrenzung. Das steuerfreie Existenzminimum lag bei 500 M. Jahreseinkommen. Bei dem Mitbestimmungsrecht der 1. Kammer hinsichtlich des konkreten Steuersatzes im Finanzgesetz war der Entwurf von der „Absicht geleitet (...), die neue Gesetzesvorlage, so weit irgend möglich, auf den Boden der gemeinsamen Anschauung beider Kammern aufzubauen“. Dabei war die Einkommensteuer ein Teil einer größeren Steuerreform auch der Ertragsteuern und des Steuerwesens der Kommunen. Die erste Beratung fand in der Abgeordnetenkammer am 17. und 18. Juli 1901 statt. Der Gesetzesentwurf wurde der Steuerkommission der 2. Kammer zur Beratung überwiesen. Unter Leitung des Zentrums-Abgeordneten Gröber tagte vom 18. De-

Gebäude- und Gewerbesteuer vom 8. August 1903. Regierungsblatt (wie Anm.5) 1903. S. 329 bzw. 344.

97 Fundiertes Einkommen ist das auf dem Vermögen beruhende Einkommen und nicht das aus Arbeit und Dienstleistung rührende Einkommen. Es fließt im Unterschied zum unfundierten Einkommen frei von Risiken wie Krankheit, Arbeitslosigkeit oder Kräfteverschleiß des Steuerpflichtigen, daher eignet es sich nach der steuerlichen Fundustheorie für besondere Besteuerung - vgl. Laura Roberts/Riccardo Mosena/Eggert Winter: Gabler Wirtschaftslexikon. ${ }^{17} 2010$. S. 1147 - fundiertes Einkommen und S. 3095 - unfundiertes Einkommen.

98 Spoerer (wie Anm. 17) S. 95. - Pistorius (wie Anm. 8) S. 24.

99 Gesetz, betreffend die Kapitalsteuer vom 8. August 1903. Regierungsblatt (wie Anm. 5) 1903. S. 313 .

100 Göz (wie Anm. 23) S. 205, 211.

101 Denkschrift (wie Anm. 17) S. 401 f. - Göz (wie Anm. 21) S. 8.

102 Verhandlungen (wie Anm 19) Beilagen-Bd. 2. S. $193 \mathrm{ff}$. 
zember 1901 bis 23. April 1902 in 25 Sitzungen die Steuerkommission der Abgeordnetenkammer. Für die Sozialdemokraten nahm Wilhelm Keil und für die Volkspartei Conrad Haußmann an den Sitzungen teil. Am 19. bzw. 25. Juni 1902 legte Gröber als Berichterstatter seinen schriftlichen Bericht vor ${ }^{103}$. In vier Sitzungen vom 25. bis 28. Juni 1902 beriet die Kammer der Abgeordneten und nahm den Entwurf mit Abänderungen mit 70 gegen 2 Stimmen sodann an. Die Kammer der Standesherren überwies den Gegenstand am 5. Juli 1902 an seine Steuerkommission. Am 25. November 1902 erstattete als Berichterstatter Geheimrat Adalbert von Heß seinen schriftlichen Bericht. Von Heß war ein renommierter Jurist, der 1894 nach Durchlauf mehrerer Staatsposten zum Präsident des Württembergischen Verwaltungsgerichtshofes berufen wurde ${ }^{104}$.

Die 1. Kammer beriet sodann in den Sitzungen vom 11. bis 18. Dezember 1902 den Entwurf ${ }^{105}$. Die Differenzpunkte zwischen beiden Kammern wurden in einem Bericht der Kommission der Kammer der Abgeordneten vom 8. April 1903 begutachtet und hinsichtlich der beiden wichtigsten Streitpunkte, der Tariffrage (Art. 18) und der Budgetfrage (Art. 19 Abs. 2) ein vermittelnder Vorschlag unterbreitet. Gemäß diesen Vorschlägen der Steuerkommission der Abgeordnetenkammer nahm die 2. Kammer nach zweitägiger Beratung am 15. Mai 1903 den Entwurf mit 71 gegen 6 Stimmen an. Sodann erstattete die Steuerkommission der Standesherren über diese Modifikationen einen weiteren am 30. Mai 1903 ausgegebenen Bericht. Daraufhin stimmte die Kammer der Standesherren nach Beratung in den Sitzungen vom 5. und 6. Juni 1903 den Beschlüssen der Abgeordnetenkammer zur Tariffrage einstimmig und zum Budgetrecht mit 23 gegen 4 Stimmen zu. Auch in den übrigen Punkten wurde weitestgehend Übereinstimmung erzielt.

Nach wiederholter Beratung der Abgeordnetenkammer am 11. Juli 1903 verblieb nur noch in vier Punkten von untergeordneter Bedeutung ein Dissens zur 1. Kammer, und das Gesetz wurde mit 61 gegen 6 Stimmen angenommen. In der Sitzung vom 16. Juli 1903 erledigte die Kammer der Standesherren schließlich die noch verbleibenden Differenzpunkte durch Beitritt zu den Beschlüssen der Abgeordnetenkammer und nahm in der Endabstimmung das Gesetz einstimmig an, so dass die Einkommensteuer nun in Württemberg nach vierzehnjähriger parlamentarischer Debatte eingeführt werden konnte ${ }^{106}$.

Betrachtet man sich die Debatte dabei genauer, ergibt sich folgendes Bild: In seinem Bericht wies von Heß darauf hin, dass man sich beim neuen Gesetzesentwurf insbesondere am badischen, sächsischen, hessischen und preußischen Recht und den hier ergangenen Novellen sowie der in Preußen vom Oberverwaltungsgericht ergangenen neueren Rechtsprechung ausgerichtet habe. Als Hauptanliegen der

103 Verhandlungen (wie Anm. 19) Beilagen-Bd.3. S. $445 \mathrm{ff}$.

104 Raberg (wie Anm. 8) S. 350 f.

105 Beschlüsse aufgrund der Verhandlungen abgedruckt in: Verhandlungen (wie Anm. 21) Beilagen-Bd.1. Beilage Nr.210 S. 358.

106 Göz (wie Anm. 21) S. 5 ff. - Pistorius (wie Anm. 8) S. 32 ff. 
württembergischen Staatsregierung formulierte er das Bestreben, die Einkommensteuer zur Hauptsteuer des direkten Staatssteuersystems zu machen. Trotz einiger Bedenken, dass das Prinzip der Besteuerung nach der Leistungsfähigkeit auf juristische Personen nicht recht passe, trat er jedoch für die Erfassung dieser Personenkreise durch die Einkommensteuer ein, weil nicht der gesamte Gewinn der entsprechenden Gesellschaften an die Anteilseigner ausgeschüttet würde und eine (gänzliche) Erfassung - also auch des bei der Gesellschaft thesaurierten Gewinns - bei diesen oft nicht praktikabel sei. Allerdings müsse eine doppelte steuerliche Erfassung bei der juristischen Person und den Anteilseignern vermieden werden. Einer gänzlichen Freistellung von Dividenden bei den Aktionären redete er aber nicht das Wort, vielmehr seien die Dividenden bis zu einem Betrag von 3\% des eingezahlten Aktien- bzw. Stammkapitals beim Gewinn und mithin der Besteuerung der Aktiengesellschaft in Abzug zu bringen. Generell hob er hervor, dass Besteuerungsgegenstand das „reine Einkommen“ sei, weshalb die Abzugsfähigkeit gewisser Aufwendungen unter diesem Gesichtspunkt auf dem Prüfstand stünde. Entsprechend seien Aufwendungen für die bloße Vermögensmehrung und somit unmittelbare Aufwendungen auf die Einkommensquelle selbst nicht abzugsfähig. Hinsichtlich des berücksichtungsfähigen Aufwandes stellte sich auch die Frage der Handhabung von Berufskleidung oder dem häuslichen Arbeitszimmer. Ein weiterer Schwerpunkt seiner Ausführung war die Frage, unter welchen Voraussetzungen Versicherungsprämien als Berufsaufwand geltend gemacht werden könnten. Weiter stellte sich die Frage, ob bei schwankenden Einkünften auf einen Durchschnittswert der letzten drei Jahre für die Besteuerung abzustellen sei. Was die zeitliche Zuordnung anbelangte, so wies er auf die Rechtsprechung des preuBischen Oberverwaltungsgerichts hin, dass bei Freiberuflern das Zuflussprinzip zu gelten habe und nicht etwa bereits die Entstehung von Honorarforderungen die Einkommensteuer auslöse. Bei der Frage des Einkommensteuertarifs begegnete von $\mathrm{He} ß$ der Forderung nach einem Spitzensatz von 6\% mit Ablehnung. Er wies in diesem Zusammenhang darauf hin, dass nur Hamburg und Lübeck einen solch hohen Steuersatz besäßen, dort aber Staats- und Kommunaleinkommensteuer zusammenfielen. Württemberg hätte im Reich aber ohnehin schon die höchste ProKopf- Besteuerung, was die direkten Steuern anbelange, so dass Zurückhaltung geboten sei. Dementsprechenden hätten bereits Vertreter der württembergischen Wirtschaft ihre Bedenken dargelegt. Er legte insofern seinem Bericht eine tabellarische Übersicht zur steuerlichen Belastung nach Einkunftshöhe geordnet von Preußen, Sachsen, Baden und Hessen bei.

Was das Mitbestimmungsrecht der 1. Kammer bei der Ausgestaltung der konkreten Tarifhöhe durch das Finanzgesetz anbelangte, sah von Heß kein Problem im Hinblick auf $₫ 181$ der Verfassung, so dass keine entsprechende Verfassungsänderung notwendig sei, und widersprach insofern ausdrücklich dem Abgeordneten Gröber vom Zentrum. Er begründete dies folgendermaßen: „Nur für die periodische, mit der Etatsverabschiedung verbundene Bewilligung der Abgaben->erhe- 
bung $<$ im Sinne des $\$ 109$ der Verfassungsurkunde ist das im $\ 181$ näher bezeichnete abgekürzte Verfahren als unerlässlich vorgeschrieben. Daraus ergiebt sich von selbst, dass für alle übrigen Gegenstände, insbesondere auch für die Feststellung der Modalitäten der Besteuerung und für die Bestimmung der Steuersätze selbst, welche der Steuererhebung zu Grunde zu legen sind, der Weg der ordentlichen Gesetzgebung, der nach der Verfassung zunächst gegebene ist“. Den Befürchtungen, dass die 1. Kammer als „Klassengesetzgebungskörper“ nur den Kompetenzzuwachs bei der Tariffrage im Finanzgesetz als Vertreter einer Klientel der besser begüterten Bevölkerungsschichten nutzen wollte, trat von Heß hierbei entschieden entgegen ${ }^{107}$.

Bei den Beratungen in der 1. Kammer vom 11. bis 18. Dezember 1903 wurde hinsichtlich der einzelnen Vorschriften insbesondere auf die preußische Regelung und der hierzu ergangenen Rechtsprechung des preußischen Oberverwaltungsgerichts abgestellt. Ernst Alban Ludwig Fürst zu Löwenstein-Wertheim-Freudenberg bemerkte zu Beginn der Debatte - und pointierte somit gleichsam die Eckpunkte der Gründe für und wider eine Einkommensteuer - zum Gesetzesvorhaben als solchem: „Die Einkommensteuer, und zwar in ihrer progressiven Form, verlangt nun ein intensives Eindringen in die persönlichen Vermögensverhältnisse des einzelnen Censisten; die individuelle Leistungsfähigkeit wird eingeschätzt; in dieser individuellen Leistungsfähigkeit liegt aber auch eine gewisse Gerechtigkeit der Besteuerung, und ich erkenne diesen Punkt an und glaube, je länger man sich in den letzten Jahren mit der Einkommensteuer beschäftigt hat, desto mehr ist die Zahl ihrer Anhänger gewachsen; sie lässt sich thatsächlich wissenschaftlich und theorethisch als eine weit vollkommenere Steuer definieren als die bisherigen Ertragsteuern. Die Ertragsteuern sind gewissermaßen nicht so biegsam, anschmiegend, sie fassen gewisse Einkommensquellen, aber sie individualisieren nicht. Ein Vortheil bei der progressiven Einkommensteuer ist auch der Schuldenabzug, der bei den Ertragsteuern bisher nicht möglich war; man kann also dem einzelnen seine Steuerpflicht weit gerechter zumessen. Dieses Prinzip der Gerechtigkeit ist es, das die Einkommensteuer immer populärer gemacht hat, aber daneben steht das ungeheuer weite Eingreifen in die persönlichen Verhältnisse“. Gleichzeitig sprach er sich dagegen aus, den Steuersatz hoch zu bemessen, insofern sah er in der Progression „eine kommunistische Gesetzgebung“.

Finanzminister von Zeyer sprach seine Hoffnung aus, dass ein Höchststeuersatz von 4,5\% die Zustimmung beider Kammern erhalten werde. Von Heß wies hinsichtlich des Höchststeuersatzes, den die Abgeordnetenkammer mit 5\% ansetzte, darauf hin, dass den höchsten Steuersatz Hessen besitze. In diesem Zusammenhang führte er unter Bezugnahme auf seinen Bericht an, dass der Württembergische Handelskammertag mit Resolution vom 5. November 1902 auf die nachtei-

107 Verhandlungen (wie Anm.21) Beilagen-Bd.1. Beilage Nr.197. S. 235 ff., 250, 252 ff., 256 ff., 258 ff., 264, 282, 284, 292 ff., 302, 304 ff., 343 ff. 
ligen Folgen für die im Aufbauprozess befindliche württembergische Industrie bei einem zu hohen Steuersatz hingewiesen habe. Dabei sei die Gesamtsteuerbelastung nicht aus dem Auge zu verlieren, die in Stuttgart für Industrieunternehmen zwischen $91 / 2$ und $133 / 5 \%$ liege. Weiter wurde die Frage problematisiert, ob das Mitbestimmungsrecht der 1. Kammer bei der Bestimmung der konkreten Höhe des Steuersatzes durch das Finanzgesetz eine Änderung der Landesverfassung - $\ 181$ - sei und damit einer Zweidrittelmehrheit bedürfe $(\$ 176 \text { S. } 2)^{108}$.

In den Beratungen am 5. und 6. Juni 1903 wurde unter anderem das $\mathrm{Zu}$ - und Abflussprinzip bei Freiberuflern wie Ärzten und Rechtsanwälten wiederum näher erörtert. Hinsichtlich des Höchststeuersatzes von 5\% empfahl von Zeyer angesichts des Umstandes, dass andernfalls das Gesetzesvorhaben sonst wiederum scheitere, die Annahme des Vorschlages der Abgeordnetenkammer. Aus gleichen Gründen empfahl von Heß die Annahme der Regelung zum Mitwirkungsrecht der 1. Kammer bei der Festlegung der konkreten Steuersätze durch das Finanzgesetz ${ }^{109}$. Schließlich wurde nach nochmaliger kurzer Beratung das Gesetz in der Sitzung vom 16. Juli 1903 angenommen ${ }^{110}$.

In seinem Bericht über die Beratungen der Steuerkommission der 2. Kammer legte Gröber u.a. unter Bezugnahme auf die neueste Gesetzgebung anderer deutscher Staaten wie Preußen, Sachsen, Baden und Hessen und der Rechtsprechung des preußischen Oberverwaltungsgericht auf folgende Punkte einen Schwerpunkt: Ergänzung der Einkommensteuer durch eine Vermögensteuer, Erörterung der steuerbaren Einkunftsquellen - so die Steuerbarkeit von Trinkgeldern, Dienstwohnungen und Spekulationsgewinnen, persönliche Steuerpflicht juristischer Personen und Personenvereinigungen, Höhe des steuerfreien Existenzminimums, Steuerbefreiungstatbestände, abzugsfähige Aufwendungen, Abzugsfähigkeit von Schuldzinsen sowie Versicherungsbeiträgen - insbesondere für Lebensversicherungen, Maßgeblichkeit der Handels- für die Steuerbilanz, Probleme der Doppelbesteuerung von Aktiengesellschaften und Anteilseignern unter Berücksichtigung wirtschaftspolitischer Erwägungen, Höhe des Spitzensteuersatz - wobei ein Steuersatz bis 6\% diskutiert wurde, die Frage des Beteiligungsrechtes der 1. Kammer bei der konkreten Höhe des Steuersatzes durch das Finanzgesetz wurde erst einmal ausgeklammert ${ }^{111}$.

In der Sitzung vom 17. Juli 1901 führte der Abgeordnete August Binz für die Volkspartei aus, dass angesichts der Unvollkommenheit der Ertragsteuern, bei denen insbesondere das Arbeitseinkommen ungleich stärker als das fundierte Einkommen besteuert würde, kein Weg an der allgemeinen Einkommensteuer vorbei-

108 Verhandlungen (wie Anm. 21) Protokoll-Bd. 1. S. 433, 436, 441, 456, 49, 495, 502, 505, $506,518 \mathrm{ff}$.

${ }_{109}$ Verhandlungen (wie Anm. 21) Protokoll-Bd.2, S. 840, 861, 867, $867 \mathrm{ff}$.

110 Verhandlungen (wie Anm. 21) Protokoll-Bd. 2. S. 1014.

111 Verhandlungen (wie Anm. 21) Beilagen-Bd. 3. S. 445, 447 ff., 461 ff., $470 \mathrm{ff}$., $473 \mathrm{ff}$., 480, $483,488,490,496,501 \mathrm{ff} ., 519,523,526 \mathrm{ff} ., 537 \mathrm{ff}$. 
führe. Er brachte aber auch den Gedanken der Vermögensteuer wieder ins Spiel. Bei der Höhe des Tarifs sah er Nachbesserungsbedarf. Gröber wies darauf hin, dass die Ertragsteuern, welche auf Durchschnittserträgen basierten, angesichts der technischen Entwicklung und der zunehmenden Entstehung von Großbetrieben nicht mehr die Wirklichkeit abbildeten. Auch Haußmann sprach sich für die Einkommensteuer aus. Keil stellte die Einkommensteuer aber in einem Zusammenhang zum gesamten Steuersystem. Da die Ertragsteuern wie die indirekten Steuern noch weiter bestünden, könne die SPD auch das Einkommensteuergesetz nicht unterstützen. Bei dem gegenwärtigen Gesetzesentwurf kritisierte er das steuerfreie Existenzminimum als zu gering, sowie die Progression als nicht ausreichend. Den Gedanken, dass das fundierte Einkommen höher belastet werden solle, erachtete er demgegenüber als zielführend. Auch die Abziehbarkeit von Schuldzinsen bei der Einkommensteuer begrüßte er, kritisierte demgegenüber aber, dass die traditionelle Nichtabziehbarkeit von Schuldzinsen bei den Ertragsteuern noch beibehalten bleibe. Die Einführung einer Vermögensteuer sowie den Ausbau der Erbschaftund Schenkungsteuer mahnte er an, insbesondere da das Reich hier den Bundesstaaten noch Gestaltungsspielraum belassen habe. Dr. Friedrich Ludwig von Geß erklärte sich demgegenüber für die Deutsche Partei mit der Einkommensteuer einverstanden und ermahnte die anderen Abgeordneten, dass dieses Steuerprojekt keinesfalls nochmals scheitern dürfe ${ }^{112}$.

In der Sitzung vom 18. Juli 1901 stellte von Zeyer klar, dass bei Wegfall der indirekten Steuern zur Kompensation die Einkommensteuer dermaßen hoch vom Tarif bemessen werden müsse, dass sie einer „Vergesellschaftlichung“ des Privateigentums gleich käme. Die Ertragsteuern durch eine Vermögensteuer zu ersetzen, würde eine solche Umwälzung des Steuersystems bedeuten, die zu so gravierenden Verschiebungen der Steuerlast führe, dass die Vermögensteuer zum jetzigen Zeitpunkt kaum Akzeptanz in der Bevölkerung fände ${ }^{113}$.

In den Debatten vom 25. bis 28. Juni 1902 wurde u. a. über die Zusammenveranlagung von Ehegatten und das steuerfreie Existenzminimum bzw. die Entlastung kinderreicher Familien disputiert. Gröber und Keil traten für einen Spitzensteuersatz von 6\% ein, während wiederum andere Abgeordnete wie beispielsweise das bevorrechtigte Mitglied Freiherr Johann Otto von Ow mahnten, die Steuerschraube aus Gründen der Wirtschaftsförderung nicht zu überdrehen. Was die Beteiligungsrechte der 1. Kammer bei der Festlegung des konkreten Steuersatzes anbelangt, wehrte sich hiergegen insbesondere Keil, der dies für eine Frage erachtete, welche zuförderst die Volksvertreter zu entscheiden hätten ${ }^{114}$.

Hinsichtlich der Abänderungsanträge der 1. Kammer musste die Steuerkommission der 2. Kammer durch Gröber einen neuerlichen Bericht vorlegen. Insbesonde-

112 Verhandlungen (wie Anm. 21) Protokoll-Bd.2. S. $1673 \mathrm{ff}$.

113 Verhandlungen (wie Anm. 21) Protokoll-Bd. 2. S. $1694 \mathrm{ff}$.

114 Verhandlungen (wie Anm. 21) Protokoll-Bd. 4. S. 2489, 2499 ff., 2500, 2509 ff., $2546 \mathrm{ff}$. 
re wurden hier die Besonderheiten bei der zeitlichen Erfassung von Honoraren der freien Berufe erörtert und die Eingabe des Württembergischen Handelskammertages zur Höhe des Steuertarifs ${ }^{115}$.

In der Sitzung vom 14. und 15. Mai 1903 wurde von der 2. Kammer weiter über die Einkommensteuer debattiert. Gröber trat dafür ein, dass Freiberufler nicht bereits bei Entstehen einer Honorarforderung Einkommensteuer zu zahlen hätten, sondern erst bei ihrer Realisation, da sie, anders als Gewerbetreibende, sich nicht mit Wechseln ohne Weiteres refinanzieren könnten. Angesichts der Intervention der Wirtschaftsvertreter sprach er sich für ein Nachgeben in der Tariffrage hinsichtlich des Spitzensteuersatzes aus. Was das Mitwirkungsrecht der Standesherren in der Tariffrage anbelangte, setzte sich Haußmann für ein Nachgeben ein, um das Einkommensteuergesetz nicht neuerlich scheitern zu lassen ${ }^{116}$. In der Sitzung vom 11. Juli 1903 wurden nur noch kleinere Punkte wie die Besteuerung von Spekulationsgewinnen besprochen ${ }^{117}$. Das Gesetzgebungsverfahren fand insofern dann seinen Abschluss.

\section{Resümee}

Das württembergische Einkommensteuergesetz entstand in einer konsequenten Entwicklung aus dem hochkomplexen Ertragsteuersystem dieses Landes. Insofern nahm es ältere eigenständige Entwicklungslinien auf, orientierte sich aber auch stark an den zeitgenössischen Einkommensteuergesetzen anderer Staaten, ohne in ein reines Kopieren zu verfallen. In Anbetracht des Umstandes, dass Württemberg als einer der letzten deutschen Staaten in einem langen und sehr sorgfältigen Gesetzgebungsprozess, der sich nicht nur in dem Kompetenzgerangel zwischen 1. und 2. Kammer bei der konkreten Ausgestaltung des Steuertarifs erschöpfte, sondern sich weitgehend an Sachfragen ausrichtete, sein Einkommensteuergesetz verabschiedete, konnten sehr moderne Ansätze aufgegriffen werden. Gleichzeitig konnte Erzberger als Reichsfinanzminister auf die in seinem Heimatland geführte recht aktuelle Diskussion bei Schaffung des Reichseinkommensteuergesetzes zurückgreifen.

Damit hat Württemberg einen wichtigen Beitrag zum modernen deutschen Steuerstaat und zum Gedanken der Besteuerung nach der Leistungsfähigkeit als Ausdruck der Steuergerechtigkeit geliefert. Insgesamt war bei allen wichtigen politischen Gruppierungen in der 2. Kammer aber auch in der 1. Kammer eine grundsätzliche Bereitschaft zur Einführung der Einkommensteuer gegeben, wenn auch insbesondere dem Zentrum und der Sozialdemokratie - bei letzterer Partei

115 Verhandlungen (wie Anm. 21) Beilagen-Bd. 5. S. $503 \mathrm{ff}$.

116 Verhandlungen (wie Anm. 21) Protokoll-Bd. 6. S. 3837 f., 3839 f., 3845 f.

117 Verhandlungen (wie Anm. 21) Protokoll-Bd. 7. S. 4724 ff. 
zumindest vom ideologischen Grundsatz her - dies Vorhaben am Herzen lag. Letztere grundsätzliche Interessenkonvergenz war ein Ausblick auf die Zusammenarbeit dieser beiden Parteien im Zuge der Weimarer Koalition einige Jahre später bei der Erzbergerschen Steuerreform auf Reichsebene, an der auch Wilhelm Keil auf Seiten der MSPD aktiv teilnahm ${ }^{118}$, wenn sich auch die Sozialdemokraten in Württemberg noch bei der Schlussabstimmung verweigert hatten.

118 Möller (wie Anm. 6) S.17f. 